\title{
Determination of spectral variations by means of component cells useful for CPV rating and design
}

Rubén Núñez*, César Domínguez, Stephen Askins, Marta Victoria, Rebeca Herrero, Ignacio Antón and Gabriel Sala

Instituto de Energía Solar, Universidad Politécnica de Madrid, Madrid, Spain

*ruben.nunez@ies-def.upm.es

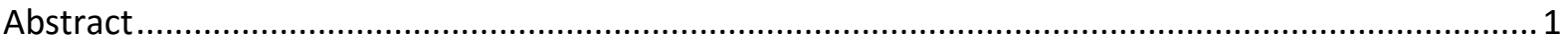

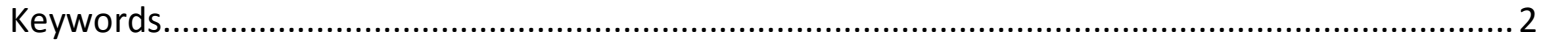

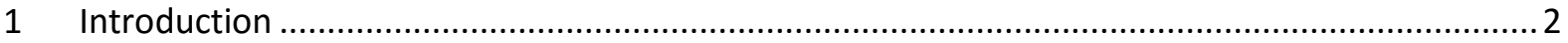

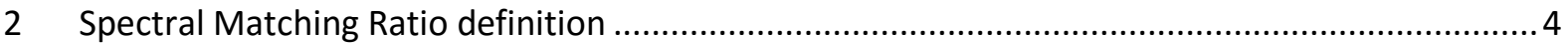

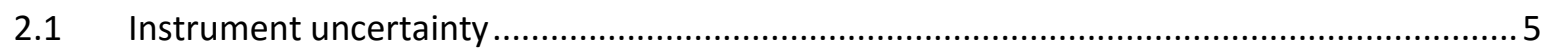

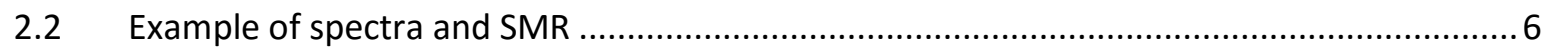

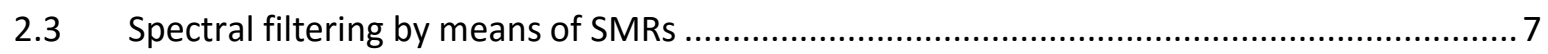

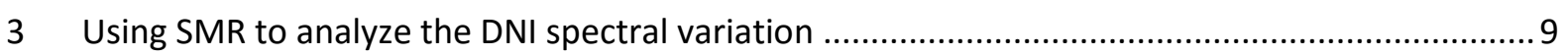

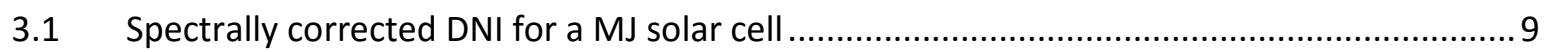

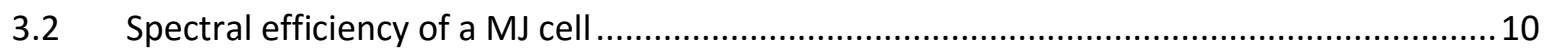

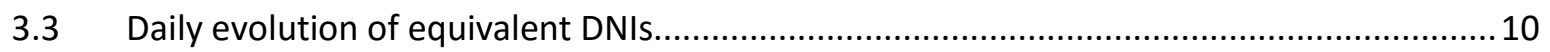

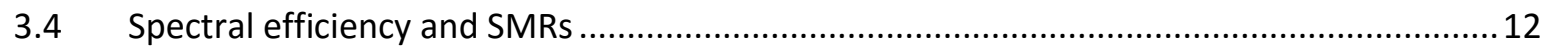

3.5 CPV power rating: spectral filtering by means of SMRs ..................................................... 14

4 Spectral characterization of a place. Energy losses due to spectral variation..............................17

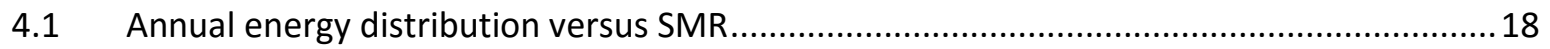

4.2 Spectral optimization of a MJ solar cell for a particular location .........................................2 20

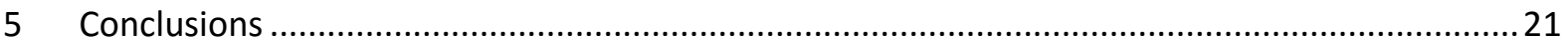

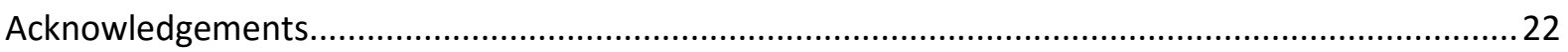

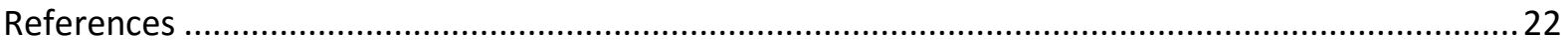

\section{Abstract}

A methodology is presented to determine both the short-term and the long-term influence of the spectral variations on the performance of Multi-Junction (MJ) solar cells and Concentrating 
Photovoltaic (CPV) modules. Component cells with the same optical behavior as MJ solar cells are used to characterize the spectrum. A set of parameters, namely Spectral Matching Ratios (SMRs), is used to characterize spectrally a particular Direct Normal Irradiance (DNI) by comparison to the reference spectrum (AM1.5D-ASTM-G173-03). Furthermore, the spectrally corrected DNI for a given MJ solar cell technology is defined providing a way to estimate the losses associated to the spectral variations. The last section analyzes how the spectrum evolves throughout a year in a given place and the set of SMRs representative for that location are calculated. This information can be used to maximize the energy harvested by the MJ solar cell throughout the year. As an example, three years of data recorded in Madrid shows that losses lower than $5 \%$ are expected due to current mismatch for state-of-the-art MJ solar cells.

\section{Keywords}

component cells; direct normal irradiance; multijunction solar cells; concentrator photovoltaics; outdoor characterization; solar spectrum

\section{Introduction}

Concentrator Photovoltaics (CPV) is currently achieving the highest efficiencies in PV [1] and seems to be a promising technology to reduce energy costs from photovoltaic conversion, especially in places with a high direct to global irradiation ratio. Modern CPV modules mostly use Multi-Junction (MJ) solar cells, that is, monolithic stacks of several subcells that are spectrally tuned to collect the maximum power from the sunlight. These subcells are connected in series, hence the changes in the incident spectrum vary the photocurrent of every subcell and influence the current of the device which is limited by the least generating subcell. Consequently, the influence that the spectral variations have on the power generated by a CPV system is of great concern. In particular, it would be interesting to know how the spectrum evolves throughout the year, what the representative spectrum for a particular location is, and how a CPV system could be optimized to maximize the energy harvested in a year. Several approaches have been proposed to account for the spectral influence on the power generation such as the direct measurement of the spectrally resolved Direct Normal Irradiance (DNI) by means of spectroradiometers [2], the atmosphere characterization based on sun photometers which provides significant parameters like aerosols content and precipitable water [3], [4], the atmosphere simulation by radiative transfer models such as MODTRAN [5], SMARTS [6] or SPCTRAL2 [7], [8], the analysis of fill factor variations [9] as a mean to determine the influence of spectrum under operating conditions, or the use of component (or isotype) cells and the associated parameters (Z parameter [10], [11], or Spectral Matching Ratio [12], [13]). Additional parameters proposed to evaluate spectral distribution of the DNI are Average Energy per Photon [14], Useful Fraction [15], Spectral Factor [16] and absolute Air Mass (AM) corrected with altitude $[17],[18]$.

A simple and affordable way to spectrally characterize the solar resource in terms of cost and ease of collecting data is to use a set of component cells [19]. A component cell is equivalent to a MJ solar cell in which only one of the subcells is electrically connected. Hence, it behaves optically as a MJ solar cell but the photogenerated current corresponds to the connected subcell regardless of the spectral distribution of the incident light. A set of component cells whose architecture is equivalent to a given MJ solar cell provides an exact or very similar spectral response to the original MJ solar cell. This means that by simply sensing a few photocurrent signals we may fully describe the spectral condition of the DNI as it affects the MJ solar cell. 
For the case of the widely used lattice matched (LM) GalnP/GalnAs/Ge triple-junction (3J) solar cells, a set of three component cells is needed which must be installed in collimating tubes and track the sun (see Figure 1). The complete instrument may be referred to as spectroheliometer and the one used in this paper was developed at Instituto de Energía Solar - Universidad Politécnica de Madrid (IES-UPM) in 2009. The instrument provides three photocurrent values, each one corresponding to one of the subcells, $I_{L, \text { top }} I_{L, \text { middle }}$ and $I_{L, \text { bottom, }}$ which are the base of the study presented in this paper.

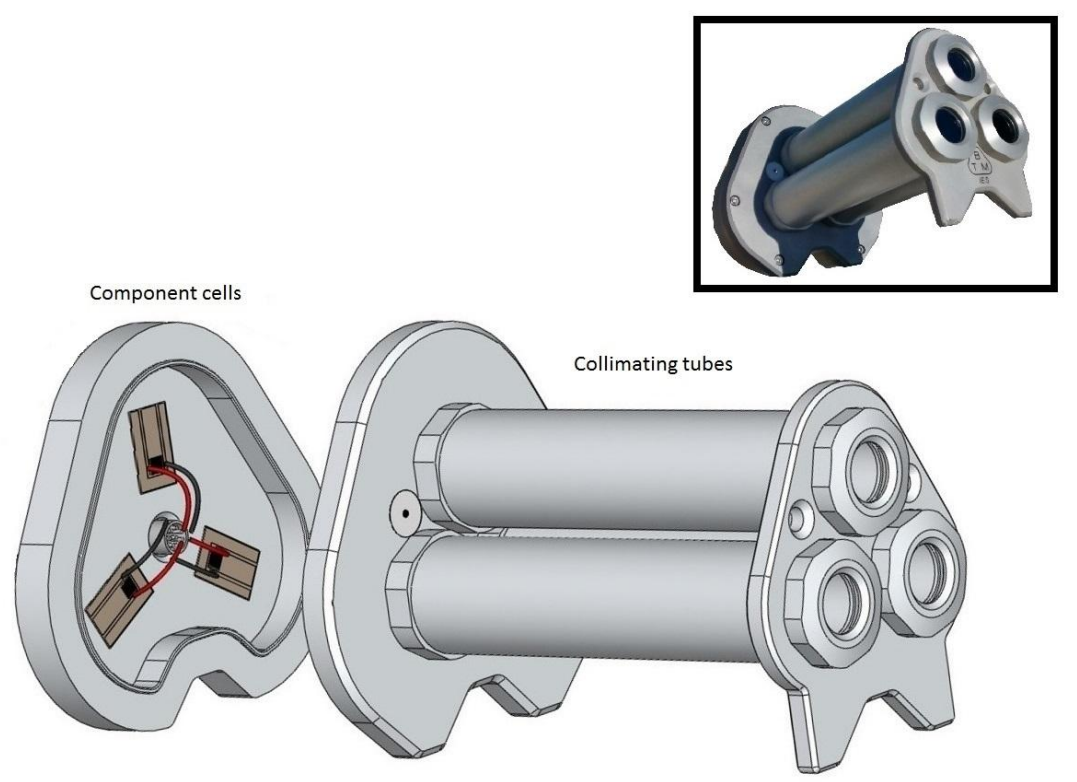

Figure 1. Schema and photography of a spectroheliometer, the instrument based on component cells used in this study.

The use of component cells offers significant advantages over other characterization instruments. On the one hand, spectroradiometers allow for a full radiometric characterization, but these instruments have significant drawbacks: their price, drifts in calibration, and the need for continuous maintenance and regular calibration to reduce uncertainty. On the other hand, radiometric simulators such as SMARTS or any other software based on atmospheric parameters require these parameters as inputs, and they are not easily measured. Moreover, they usually require expensive sun photometers, such as the ones used in the AERONET network [20], or must rely on high uncertain satellite data [21], [22].

This paper is structured in three sections. The first begins by reviewing the definition of Spectral Matching Ratio (SMR) [12]. Then, an analysis of the uncertainty associated to SMR is carried out and some examples of SMR application are shown. At the end of the section, results regarding the spectral filtering using SMR for the case of MJ solar cells are presented.

The second section is devoted to the analysis of the spectral variation of the DNI. First, the concept of "MJ equivalent DNI" is introduced as the spectrally corrected DNI for a given MJ solar cell technology. Second, the concept of "spectral efficiency" is presented. Following that, the daily evolution of both parameters, "MJ equivalent DNI" and "spectral efficiency", as well as their relationship with SMR are addressed. Before concluding the section, the analysis of spectral filtering is tackled once again but, in this case, from the point of view of the rating of a complete CPV system (comprising not only the solar cell but also the optics). 
Finally, the third and last section deals with the spectrum evolution throughout a year in a particular place, defining the most representative spectrum by means of SMR indexes, and then proposing a methodology for the optimization of the MJ cells to maximize the energy harvested during a year.

\section{Spectral Matching Ratio definition}

The Spectral Matching Ratio (SMR) quantifies a particular irradiance spectrum by comparing it to a reference spectrum, i.e. AM1.5D-G173-03 [23]. SMR is defined as the ratio between the currents photogenerated by two subcells under the spectrum in study, divided by the same ratio under the reference spectrum [13], [12], and can be calculated as:

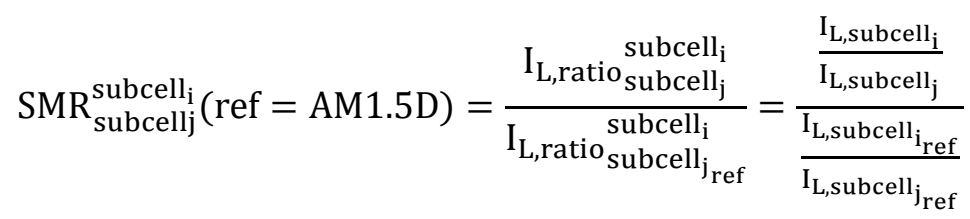

where $\mathrm{I}_{\mathrm{L}, \text { subcell }} \mathrm{i}$ represents the photocurrent of subcell $\mathrm{i}$ when illuminated with a particular spectral irradiance distribution and $\mathrm{I}_{\mathrm{L} \text {,subcell }} \mathrm{i}_{\text {ref }}$ stands for the photocurent of subcell $\mathrm{i}$ under the reference spectrum. From now on we will assume that the aforementioned MJ solar cell and the component cells used to determine the set of photocurrents and consequently SMRs are of the same technology, i.e., they have the same relative spectral responses. The results presented in this paper are based on LM GalnP/GalnAs/Ge solar cells but similar results can be obtained with different 3J solar cell architectures.

Although the definition of SMR is similar to that of the Spectral Mismatch Factor (MM) [24] used in the calibration of solar cells, SMR indexes are intended to be used for the evaluation of the spectrum while MM gives an idea about how well a solar cell and a reference cell are matched. MM compares a solar cell under test and a reference cell and, if $\mathrm{MM}$ equals one, it means that they are perfectly matched, i.e., both have the same relative spectral response or the relative shape of reference and simulated spectra are the same. However, SMR indexes compares a spectrum to the reference one by means of the photocurrents generated by the subcells of a MJ solar cell and, if SMR equals one, it means that a particular spectrum is equivalent to the reference one in the sense that both spectra produce the same balance between the subcells photocurrents.

Considering, for example, a $3 \mathrm{~J}$ solar cell and its corresponding component cells, three spectral indexes can be defined: $\mathrm{SMR}_{\text {mid }}^{\text {top }}, \mathrm{SMR}_{\text {bot }}^{\text {top }}, \mathrm{SMR}_{\text {bot }}^{\text {mid }}$ where the scripts top, mid and bot stand for the top GalnP subcell, the middle GalnAs subcell and the bottom Ge subcell respectively. Two of these SMRs (one is redundant) form a set of indexes that fully characterize the spectral irradiance for that particular MJ solar cell technology. As stated before, two spectra can be considered equivalent for that particular MJ solar cell when they attain the same SMRs or, in other words, the subcells within a MJ solar cell produce the same current ratios under both spectra. It must be pointed out that this spectral equivalence definition does not consider the absolute value of their corresponding photocurrents. Instruments based on component cells should be used together with an absolute irradiance sensor such as a Normal Incidence Pyrheliometer for outdoor characterization or a calibrated irradiance module or similar with CPV solar simulators [12].

Consequently, from the point of view of a MJ solar cell composed of $\mathrm{n}$ subcells, the spectral variation can be described by n-1 SMR values. In the case of a 3J solar cell, $\mathrm{SMR}_{\text {mid }}^{\text {top }}$ and $\mathrm{SMR}_{\text {bot }}^{\text {mid }}$ are preferred over SMR $\mathrm{b}_{\text {bot }}^{\text {top }}$ because they decouple fairly well the effects of $A M$ and aerosol optical depth (AOD) , 
both of which mainly affect the top and middle spectral regions, with the precipitable water PW, which mainly affects the middle and primarily bottom spectral regions [25].

\subsection{Instrument uncertainty}

In this paragraph we intend to estimate the uncertainty of SMR values as measured with a spectroheliometer. According to the ISO Guide to the Expression of Uncertainty in Measurement [26] evaluation of the sources of uncertainty are categorized in type A (uncertainty estimated using statistics, i.e., obtained from repeated observations) and type B (uncertainty estimated from any other source, e.g., calibration certificates, manufacturer's specifications, previous experience with similar measurements...)

On the one hand, type A evaluation of uncertainty is based on statistical analysis of series observation. The short-circuit current produced by every component cell $I_{L, \text { subcell } i}$ is obtained through the measured voltage $V_{i}$ and the shunt resistance $R_{i}$, while the instrument is placed in a meteorological sun tracker and the data is collected by a datalogger, and therefore type $A$ analysis may be used for this parameter. When repeatability conditions are imposed (clean windows, irradiation over $700 \mathrm{~W} \cdot \mathrm{m}^{-2}$ and DNI stability, as defined in section 2.3 ), the type A uncertainty for the short-circuit current of a component cell has been found to be lower than $0.2 \%$.

On the other hand, the main contribution to type B uncertainty for the short-circuit current of a component cell $U_{I_{L, \text { subcell } i}}$ is the tolerance of the shunt resistances $(0.1 \%) U_{R_{i}}$. The additional contributions to uncertainty caused by the pointing accuracy of the tracker $\left(0.1^{\circ}\right.$ for a solar tracker for radiation measuring instruments) and the resolution of the data acquisition instruments (20 bits and $10 \mathrm{~V}$ full scale) can be considered negligible.

Taking into account both $A$ and $B$ contributions, total uncertainty when measuring short-circuit current of a component cell can be estimated as $U_{I_{L, \text { subcelli }}}=0.22 \%$, according to [26].

To determine the uncertainty of the short-circuit current of every subcell under the reference spectrum $U_{L, \text { subcell }} i_{\text {ref }}$ we should consider the uncertainty of the calibration provided by the manufacturer ( $3 \%$ for all the component cells) and the uncertainty of the protective window transmissivity $U_{\text {Window }}$ (maximum value of the three component cells $0.35 \%$ ). Then $U_{I_{L, \text { subcell }}}{ }_{i_{\text {ref }}}=$ $3.02 \%$ (before rounding to two significant digits as stated in [26]). Errors due to the differences in the spectral response of the component cells at different temperatures have been neglected.

The uncertainty in the determination of SMR $U_{S M R}$ is calculated based on the definition of SMR given in Equation (1):

$$
U_{S M R}=\sqrt{\left(\frac{\partial S M R}{\partial I_{L, \text { subcell } i}} \mathrm{U}_{I_{L, \text { subcell } i}}\right)^{2}+\left(\frac{\partial S M R}{\partial I_{L, \text { subcell } j}} \mathrm{U}_{I_{L, \text { subcell } j}}\right)^{2}+}
$$

We have determined $U_{S M R}=4.3 \%$, demonstrating that SMR uncertainty is basically determined by the uncertainty of the calibration of the component cells at reference conditions. 


\subsection{Example of spectra and SMR}

As previously stated, SMR indexes can be used to describe the spectrum of the irradiance incident on a MJ solar cell. As an example, two different spectra (corresponding to midday and sunset of the same day in Madrid) are shown in Figure 2 together with the reference spectrum AM1.5D-G173-03 and the quantum efficiency of three component cells corresponding to a LM GaInP/GalnAs/Ge solar cell.

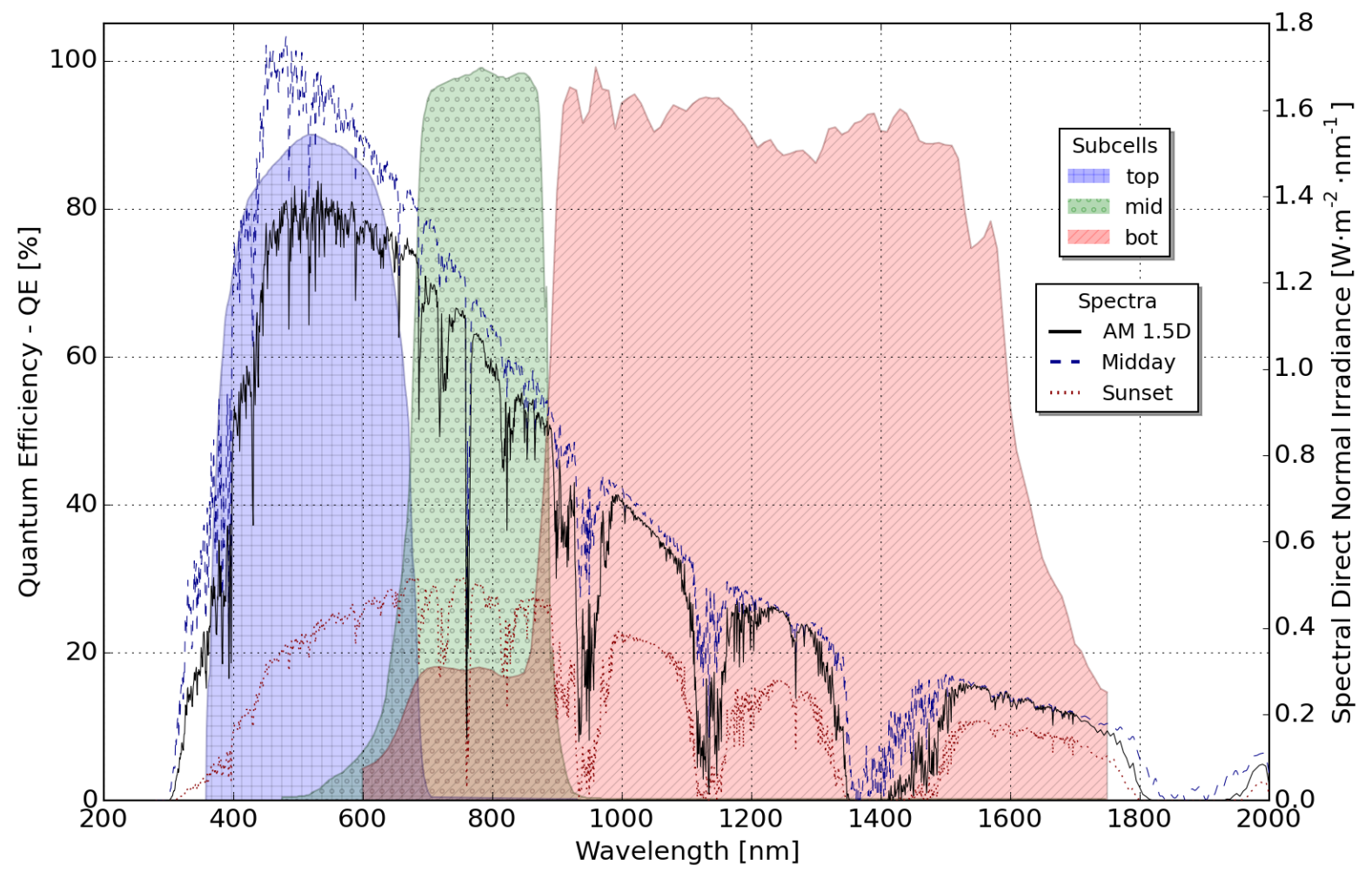

Figure 2. Quantum efficiency of the component cells used in this study. The reference spectrum AM1.5D G173-03 is also plotted together with two other spectra representative of midday and sunset moments.

The photocurrent generated by every subcell and the corresponding $\mathrm{SMR}_{\text {mid }}^{\text {top }}$ and $\mathrm{SMR}_{\mathrm{bot}}^{\mathrm{mid}}$ parameters are calculated for every spectra showed in Figure 2 (Table 1). The spectral content of the DNI depends strongly on the solar elevation and aerosol content in the atmosphere, which also affects the SMR values [25]. High $\mathrm{SMR}_{\text {mid }}^{\text {top }}$ values indicate blue-shifted spectrum probably caused by low AM values or low aerosol content in the atmosphere (i.e. low AOD). Generally speaking, the lower the $\mathrm{SMR}_{\mathrm{bot}}^{\mathrm{mid}}$ is, the drier the atmosphere (lower PW) is, as it is mainly influenced by the water absorption bands.

Table 1. SMR values calculated for the three spectra plotted in Figure 2.

\begin{tabular}{|l|l|l|}
\hline spectrum & SMR $_{\text {mid }}^{\text {top }}$ & SMR $_{\text {bot }}^{\text {mid }}$ \\
\hline Midday & 1.08 & 0.89 \\
\hline Sunset & 0.69 & 0.84 \\
\hline AM1.5D G-173-03 & 1 & 1 \\
\hline
\end{tabular}


According to the definition in Equation (1), the reference spectrum has SMR values equal to 1 . Therefore, the closer the SMRs are to unity, the more similar the photocurrent ratios of the MJ solar cell under the particular spectrum are to their ratios under the reference spectrum.

\subsection{Spectral filtering by means of SMRs}

In order to graphically describe the spectral changes in the DNI in a particular location (Madrid, in this analysis) throughout a year, a 8000 representative spectra have been generated using SMARTS [6] using the following inputs: altitude $695 \mathrm{~m}$, mean air pressure $933 \mathrm{hPa}$, and an urban model for aerosol. The atmospheric parameters have been swept within the ranges that include $90 \%$ of the accumulated irradiation in Madrid, i.e., AOD at $500 \mathrm{~nm}$ is between 0.02 and 0.6 , PW ranges from 0.3 to $3 \mathrm{~cm}$ and AM is between 1 and 2.25 [25]. Other SMARTS parameters with less influence on this analysis, such as ozone or $\mathrm{CO}_{2}$, have been set to reference spectrum conditions.

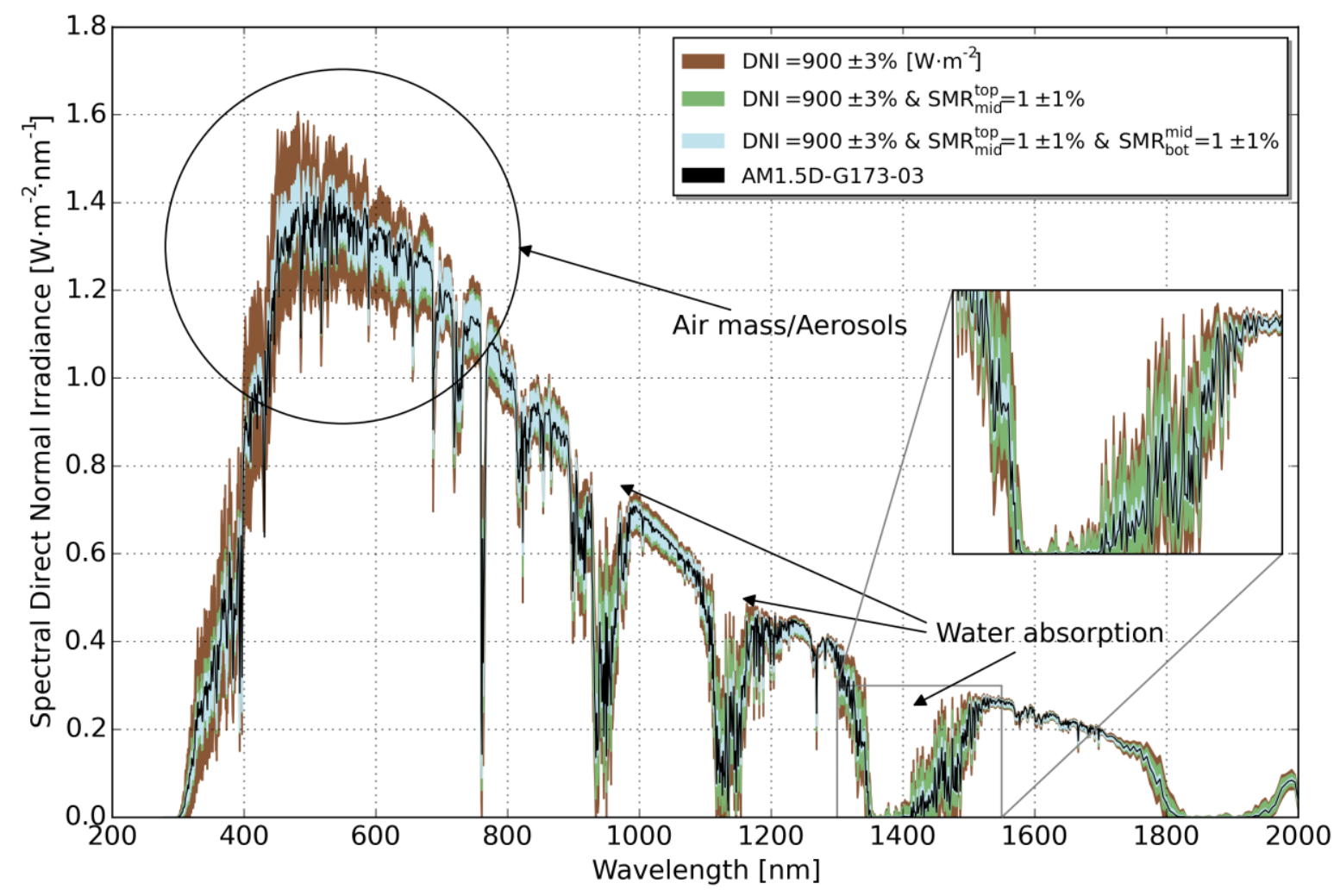

Figure 3. Representative collection of spectra for Madrid throughout a year generated using SMARTS. Spectra are filtered incrementally by imposing direct normal irradiance $\mathrm{DNI}=900 \pm 3 \%$ $\mathrm{W} \cdot \mathrm{m}^{-2}$, spectral matching ratio $S M R_{\text {mid }}^{\text {top }}=1 \pm 1 \%$ and $S M R_{\text {bot }}^{\text {mid }}=1 \pm 1 \%$. Adding the filter $S M R_{\text {mid }}^{\text {top }}=1 \pm 1 \%$ clearly reduces the dispersion of spectra in the top subcell region mainly influenced by AM and aerosols content. Imposing additionally $S M R_{\text {mid }}^{\text {top }}=1 \pm 1 \%$ and $S M R_{b o t}^{\text {mid }}=1 \pm 1 \%$ reduces the dispersion in the bottom subcell region, where there are several water absorption peaks.

A first application of component cells and SMRs is the filtering of operating conditions to ensure certain prevailing spectral conditions for both outdoor and indoor measurements and power rating of CPV cells, modules or systems based on MJ solar cells [10], [13], [19], [27], [28]. This use is widely accepted by the CPV community [29] and it is included in the current draft of the power rating standard [30]. In order to show how SMR filtering reduces spectral dispersion, several subsets of the aforementioned 8000 spectra are represented in Figure 3 after applying consecutive filters, more restrictive at every step, approaching the reference spectrum AM1.5D-G173 which is represented in 
black. First, spectra whose total irradiance value is within $\pm 3 \%$ of the reference spectrum irradiance $\left(900 \mathrm{~W} / \mathrm{m}^{2}\right)$ are shown in brown. This is the only condition that can be limited by means of a pyrheliometer. Second, the condition $\mathrm{SMR}_{\text {mid }}^{\text {top }}=1 \pm 1 \%$ is added in green. Latter spectra in light blue are those which besides previous requirements also meet $\mathrm{SMR}_{\mathrm{bot}}^{\mathrm{mid}}=1 \pm 1 \%$. It can be noted how well the filtered spectra resemble the reference AM1.5D-G173 when the triple condition is applied (DNI = $900 \pm 3 \% \mathrm{~W} / \mathrm{m}^{2} ; \mathrm{SMR}_{\mathrm{mid}}^{\mathrm{top}}=1 \pm 1 \% ; \mathrm{SMR}_{\mathrm{bot}}^{\mathrm{mid}}=1 \pm 1 \%$ ).

There is currently an open discussion in the CPV community about the limits of SMR filters to establish prevailing spectral conditions for rating purposes [30]. The suitability of the limits will be discussed later in the paper. In this section we will focus on the probability of occurrence in Madrid of such prevailing conditions for several filter conditions both for DNI and spectra. The study is based on experimental data of minute-resolved SMR measurements using the spectroheliometer throughout 2013. Spurious data caused by tracking misalignment or unstable irradiances (filter conditions: $100<\mathrm{DNI}<1100 \mathrm{~W} \cdot \mathrm{m}^{-2},|\mathrm{dDNI} / \mathrm{dt}|<10\left(\mathrm{~W} \cdot \mathrm{m}^{-2}\right) / \mathrm{min}$ ) has been removed. In addition, the spectroheliometer calibration has been continuously verified by comparison of the irradiances provided by the component cells to the pyrheliometer under reference spectral conditions given by $\mathrm{SMR}_{\text {mid }}^{\text {top }}=1 \pm 1 \%$ and $\mathrm{SMR}_{\mathrm{bot}}^{\mathrm{mid}}=1 \pm 1 \%$ (to assure low long term drift in the component cells calibration). Table 2 summarizes the number of days per year that each condition is met for two DNI filters (DNI = $900 \pm 3 \%$ and $\left.\mathrm{DNI}>700 \mathrm{~W} \cdot \mathrm{m}^{-2}\right)$ and two SMR ranges around $1( \pm 1 \%$ and $\pm 2.5 \%)$. The condition of DNI $>700 \mathrm{~W} \cdot \mathrm{m}^{-2}$ has been defined as 'clear sky conditions'.

Table 2. Number of days per year that several filtering conditions are met in Madrid during 2013.

SMR stands for Spectral Matching Ratio as defined in Equation (1) and measured using a spectroheliometer. Additional filters for unstable irradiances were applied in all cases (filtering conditions: $\left.100<\mathrm{DNI}<1100 \mathrm{~W} \cdot \mathrm{m}^{-2},|\mathrm{dDNI} / \mathrm{dt}|<10\left(\mathrm{~W} \cdot \mathrm{m}^{-2}\right) / \mathrm{min}\right)$. The average and the standard deviation $\left(\mathrm{W} \cdot \mathrm{m}^{-2}\right)$ of the population of DNI values are included in brackets for the cases of wide DNI filters (DNI $\left.>700 \mathrm{~W} \cdot \mathrm{m}^{-2}\right)$.

\begin{tabular}{|c|c|c|c|c|c|c|}
\hline $\begin{array}{c}100<B<1100 \\
W \cdot \mathrm{m}^{-2} \\
|\mathrm{~dB} / \mathrm{dt}|<10 \\
\left.\mathrm{~W} \cdot \mathrm{m}^{2} / \mathrm{min}\right) \\
\text { Filtering } \\
\text { condition } \\
\end{array}$ & $\begin{array}{c}\text { DNI }=900 \pm 3 \% \\
\text { No SMR filt. }\end{array}$ & $\begin{array}{l}\mathrm{DNI}=900 \pm 3 \% \\
\mathrm{SMR}_{\text {mid }}^{\text {top }}=1 \pm \varepsilon \%\end{array}$ & $\begin{array}{l}\mathrm{DNI}=900 \pm 3 \% \\
\mathrm{SMR}_{\text {mid }}^{\text {top }}=1 \pm \varepsilon \% \\
\mathrm{SMR}_{\text {bot }}^{\text {mid }}=1 \pm \varepsilon \%\end{array}$ & $\begin{array}{l}\text { DNI > } 700 \\
\text { No SMR filt. }\end{array}$ & $\begin{array}{c}\mathrm{DNI}>700 \\
\mathrm{SMR}_{\text {mid }}^{\text {top }}=1 \pm \varepsilon \%\end{array}$ & $\begin{array}{c}\mathrm{DNI}>700 \\
\mathrm{SMR}_{\text {mid }}^{\text {top }}=1 \pm \varepsilon \% \\
\mathrm{SMR}_{\text {bot }}^{\text {mid }}=1 \pm \varepsilon \%\end{array}$ \\
\hline $\begin{array}{c}\varepsilon=1 \% \text { for SMRs } \\
\text { when applicable }\end{array}$ & \multirow{2}{*}{249} & 90 & 34 & \multirow{2}{*}{$\begin{array}{c}316 \\
{[\text { Avg }=856]} \\
{[S t d=76]}\end{array}$} & $\begin{array}{c}217 \\
{[\text { Avg }=860]} \\
{[S t d=53]}\end{array}$ & $\begin{array}{c}74 \\
{[\text { Avg }=848]} \\
{[S t d=41]}\end{array}$ \\
\hline $\begin{array}{c}\varepsilon=2.5 \% \text { for } \\
\text { SMRs } \\
\text { when applicable }\end{array}$ & & 140 & 94 & & $\begin{array}{c}249 \\
{[\text { Avg }=864]} \\
{[S t d=55]}\end{array}$ & $\begin{array}{c}155 \\
{[\text { Avg }=860]} \\
{[S t d=45]}\end{array}$ \\
\hline
\end{tabular}

It must be pointed out that, for the case of Madrid, very narrow filtering ( $\pm 1 \%$ for SMRs) would lead to few days where those outdoor operating conditions are met so, from the point of view of probability of occurrence, wider filters such as $\pm 2.5 \%$ may be more recommended for rating procedures. In addition, there is a strong limitation between the filters over the DNI and the SMRs. Due to the climate of Madrid, almost $50 \%$ of the days where the double condition $\mathrm{SMR}_{\text {mid }}^{\text {top }}=1$ \& $\mathrm{SMR}_{\mathrm{bot}}^{\mathrm{mid}}=1$ happens, the irradiance is in the range of $900 \pm 3 \% \mathrm{~W} \cdot \mathrm{m}^{-2}$ (34 days of 74 to be exact). 
Under this triple condition the solar spectra resembles the reference AM1.5D-G173 as shown in Figure 3. In fact, the average values of the DNI for the SMRs $=1 \pm \varepsilon \%$ filters are between 848 and 864 $\mathrm{W} \cdot \mathrm{m}^{-2}$ which shows again that, for the climate of Madrid, a high correlation is found between SMRs close to one and DNI values close to $900 \mathrm{~W} \cdot \mathrm{m}^{-2}$ for "clear sky" conditions (DNI $>700 \mathrm{~W} \cdot \mathrm{m}^{-2}$ ).

Summarizing this section, the threefold condition $\left(\mathrm{SMR}_{\mathrm{mid}}^{\mathrm{top}}=1 \pm 1 \%\right.$; $\mathrm{SMR}_{\mathrm{bot}}^{\mathrm{mid}}=1 \pm 1 \%$; $\mathrm{DNI}=900 \pm 3 \%$; $\mathrm{W} \cdot \mathrm{m}^{-2}$ ) leads to a solar spectrum in Madrid very similar to the reference AM1.5D-G173, but this conditions only happens about 30 days per year. If the DNI condition is relaxed, i.e., to a simple clear sky condition such as DNI > $700 \mathrm{~W} \cdot \mathrm{m}^{-2}$, prevailing conditions for CPV based on MJ solar cells can be defined, based on $S M R s=1 \pm \varepsilon \%$. Accordingly to SMR definition, a bare MJ solar cell would generate the same current under any spectra of the same SMRs, but this is not necessary true for a CPV module or systems including optics or temperature issues. From the point of view of occurrence, SMR ranges of $\pm 2.5 \%$ seem to be adequate for limiting prevailing conditions but their suitability must be proved.

\section{Using SMR to analyze the DNI spectral variation}

\subsection{Spectrally corrected DNI for a MJ solar cell}

For a particular MJ solar cell technology, equivalent direct normal irradiances, $\mathrm{B}_{\text {subcell }}$, are defined as the ratios of the photocurrents generated by each subcell under a particular DNI to the photocurrents of the same subcell under the reference spectrum AM1.5D-G173-03 [19]. In the case of $3 \mathrm{~J} \mathrm{solar}$ cells, a set of equivalent DNIs, $B_{\text {top }}, B_{\text {middle }}$ and $B_{\text {bottom, }}$ can be defined as

$$
\mathrm{B}_{\text {subcell }_{\mathrm{i}}}=\frac{\mathrm{I}_{\mathrm{L}, \text { subcell }_{\mathrm{i}}}}{\mathrm{I}_{\mathrm{L}, \text { subcell }_{\text {ref }}}} \mathrm{B}_{\text {ref }}
$$

where is $B_{r e f}$ is the reference DNI at which the calibrated value $\mathrm{I}_{\mathrm{L}, \text { subcell }}$ iref $_{\text {ref }}$ is obtained. Using this definition, two spectra that produce the same photocurrent in a particular subcell can be considered "equivalent" for that particular subcell. Hence, SMR can also be defined using $B_{\text {subcell }_{i}}$ :

$$
\mathrm{SMR}_{\text {subcell }_{\mathrm{j}}}^{\text {subcell }_{\mathrm{i}}}=\frac{\mathrm{B}_{\text {subcell }_{\mathrm{i}}}}{\mathrm{B}_{\text {subcell }_{\mathrm{j}}}}
$$

For a $3 \mathrm{~J}$ solar cell, a spectrum equivalent to reference meets the condition $\mathrm{B}_{\text {top }}=\mathrm{B}_{\text {middle }}=\mathrm{B}_{\text {bottom, }}$ which is equivalent to $\mathrm{SMR}_{\text {mid }}^{\text {top }}=\mathrm{SMR}_{\text {bot }}^{\text {mid }}=1$.

A spectrally corrected DNI, for a particular MJ solar cell technology, can be defined to determine the current generated by the device. This MJ equivalent $\mathrm{DNI}\left(\mathrm{B}_{\mathrm{MJ}}\right)$ is defined using the photocurrent generated by the MJ solar cell under a certain spectrum $I_{L}$, and the photo response under the reference spectrum $\mathrm{I}_{\mathrm{L}_{\text {ref }}}$

$$
\mathrm{B}_{\mathrm{MJ}}=\frac{\mathrm{I}_{\mathrm{L}}}{\mathrm{I}_{\mathrm{Lref}}} \mathrm{B}_{\text {ref }}
$$

where $I_{L}$ is calculated as the minimum among the photocurrents generated by the subcells within the $M J$ device, i.e., $I_{L}=\min \left(I_{L, \text { top }}, I_{L, \text { mid, }} I_{L, \text { bot }}\right)$ for $3 J$ cells. Likewise, at reference spectrum, $I_{L-\text { ref }}=$

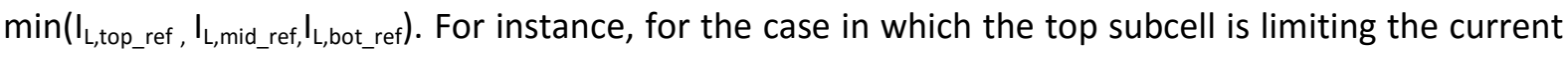
of the $3 \mathrm{~J}$ device under the reference spectrum $\left(\mathrm{I}_{\mathrm{L}_{\text {ref }}}=\mathrm{I}_{\mathrm{L} \text {,top_ref }} ; \mathrm{I}_{\text {ratio }}\right.$ top $_{\text {ref }}<1 ; \mathrm{I}_{\text {ratio }}$ bot $\left._{\text {ref }}<1\right)$, as commonly happens in LM GaInP/GalnAs/Ge under concentrators, Equation (5) can be expressed as: 


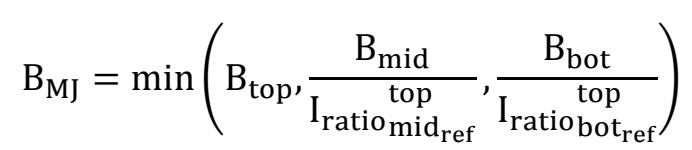

Similar expressions can be obtained in case of a different subcell current limitation at the reference spectrum.

For LM GalnP/GalnAs/Ge solar cells, it can be assumed that the bottom subcell does not ever limit the current of the device under operating conditions $\left[\mathrm{I}_{\text {ratio }}\right.$ top $\left.t_{\text {ref }}<<1\right]$. Then Equation (6) can be further simplified as:

$$
\mathrm{B}_{\mathrm{MJ} \text { GaInP/GaInAs/Ge }}=\min \left(\mathrm{B}_{\text {top }}, \frac{\mathrm{B}_{\text {mid }}}{\mathrm{I}_{\text {ratio }_{\text {mid }}}^{\text {top }}}\right)
$$

\subsection{Spectral efficiency of a MJ cell}

Taking into account that $B_{M J}$ is directly proportional to the photocurrent generated by a MJ device, a spectral efficiency factor $\eta_{\text {spectral }}$ can be defined as the ratio between that irradiance and the DNI measured with a Normal Incident Pyrheliometer (NIP), $\mathrm{B}_{\mathrm{NIP}}$ :

$$
\eta_{\text {spectral }}=\frac{\mathrm{B}_{\mathrm{MJ}}}{\mathrm{B}_{\mathrm{NIP}}}
$$

For a specific location, $\eta_{\text {spectral }}$ varies throughout the day influenced by the sun elevation and variations in the atmosphere. When the photocurrent balance among the subcells of the MJ device is the same as in the reference spectrum, i.e. $B_{\text {top }}=B_{\text {mid }}=B_{\text {bot }}$ or $\operatorname{SMR}_{\text {mid }}^{\text {top }}=1$ and $\mathrm{SMR}_{\text {bot }}^{\text {mid }}=1$, $\eta_{\text {spectral }}$ is equal to one. Note that $\eta_{\text {spectral }}$ could be slightly greater than unity for a particular MJ solar cell technology if such cell performs better under a certain spectrum than under the reference one.

\subsection{Daily evolution of equivalent DNIs}

The plot on the left of Figure 4 shows the daily evolution on a summer day in Madrid of equivalent DNIs ( $B_{\text {top }}, B_{\text {middle }}$ and $B_{\text {bottom }}$ ) measured by means of $L M$ GalnP/GalnAs/Ge component cells. In this case, under the reference spectrum, $\mathrm{I}_{\text {ratio }}$ midt $_{\text {ref }} \cong 1$ and the bottom subcell generates an extra $60 \%$ photocurrent.

At the beginning of the day, AM is higher than at midday, hence, the spectrum is more attenuated at the top subcell region due to scattering of the sunlight in the atmosphere which produces a redshifted spectrum. The same can be said at the end of the day. At midday, when the sun is at its highest elevation the path travelled by the light through the atmosphere is shorter. The equivalent irradiance for the top subcell is higher than for the middle, producing a blue-shifted spectrum. Both periods can be seen in plot on the right of Figure 4. The two moments of the day at which the spectrum is equivalent to the reference (they produce the same current ratio) are also marked. In them, the three equivalent DNIs are equal $\left(B_{\text {top }}=B_{\text {middle }}=B_{\text {bottom }}\right)$ and both SMRs are equal to one $\left(\mathrm{SMR}_{\text {mid }}^{\mathrm{top}}=1\right.$ and $\left.\mathrm{SMR}_{\text {bot }}^{\mathrm{mid}}=1\right)$.

The graph on the right side of Figure 4 displays the daily evolution of the MJ equivalent DNI ( $\left.B_{M J}\right)$ along with the DNI measured with a standard pyrheliometer $\left(B_{N I P}\right)$. If the $M J$ device has been optimized in terms of subcell photocurrent balances for the reference spectrum, its performance under any other spectrum will be lower. This is reflected in a lower value of $B_{M J}$ compared to $B_{N I P}$ as can be clearly observed in Figure 4. Only under a spectral irradiance equivalent to the reference $\left(\mathrm{SMR}_{\text {mid }}^{\text {top }}=1\right.$ and $\left.\mathrm{SMR}_{\text {bot }}^{\text {mid }}=1\right)$ both $\mathrm{B}_{\mathrm{MJ}}$ and $\mathrm{B}_{\mathrm{NIP}}$ match and consequently $\eta_{\text {spectral }}=1$. This condition is met at about $8 \mathrm{~h}$ and $16 \mathrm{~h}$ for the day shown in Figure 4 . For the rest of the time the spectrum 
mismatch causes a limitation of either the top or the middle subcell current and a corresponding decrease in the spectral efficiency that expresses the photocurrent loss of a MJ device, associated with the current mismatch among the subcells, under a particular spectral distribution of the DNI compared with respect to the reference spectrum.
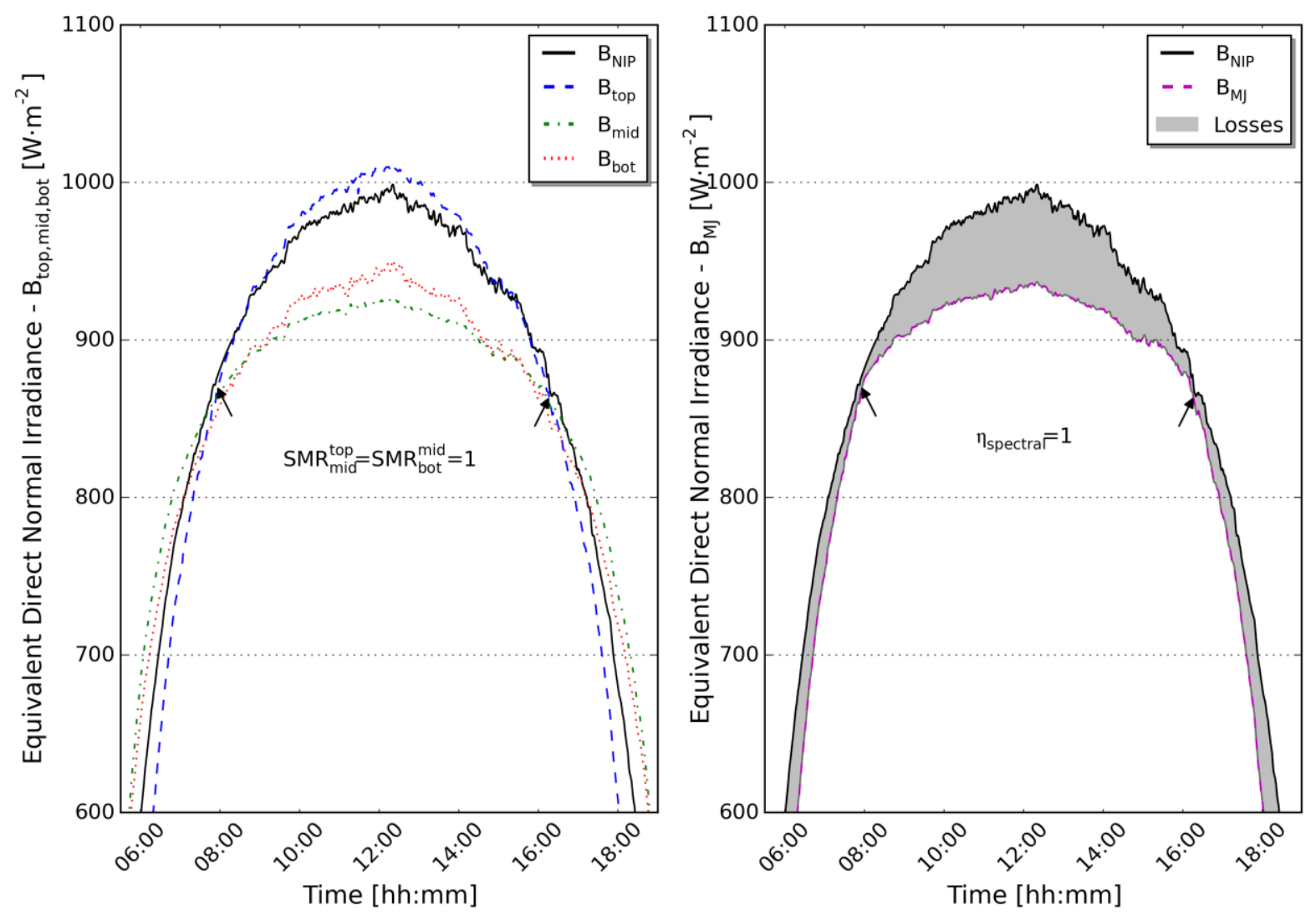

Figure 4. Equivalent direct normal irradiance (DNI) for every subcell within a triple-junction solar cell, $B_{\text {top }}, B_{\text {mid }}$, and $B_{\text {bot }}$, compared to DNI measured with a pyrheliometer $B_{\text {NIP }}$ (left). Equivalent DNI for a MJ solar cell $B_{M J}$ and DNI measured with a pyrheliometer $B_{\text {NIP }}$ (right) At the particular moments when the three equivalent DNI match, spectral matching ratios (SMRs) are equal to one indicating that the spectrum is equivalent to reference AM1.5D-G173-03. When $B_{M J}$ is identical to $B_{\text {NIP, }} \eta_{\text {spectral }}$ is equal to one. Photocurrent losses caused by the differences between the spectral distribution of the DNI at any given moment and the reference spectrum are shown as the grey area between $B_{\text {NIP }}$ and $B_{M J}$.

As shown in Table 2, the triple match situation $\left(B_{\text {top }}=B_{\text {middle }}=B_{\text {bottom }}\right.$ and $\operatorname{SMR}_{\text {mid }}^{\text {top }}=1$ and $\mathrm{SMR}_{\mathrm{bot}}^{\mathrm{mid}}=1$ ) in the case of Madrid only takes place in a limited numbers of days per year. However since the bottom subcell does not limit the current of LM GalnP/GalnAs/Ge solar cells for most of the operating conditions, for this technology we can consider a spectrum equivalent to the reference

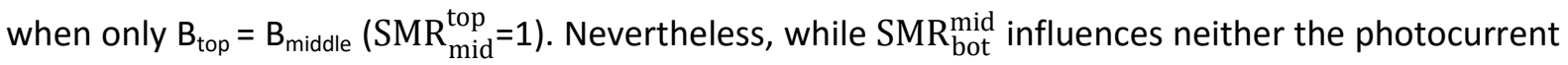
of the MJ solar cell nor $B_{M J}$ for this cell technology, it does affect the DNI value measured with the pyrheliometer $\left(B_{\text {NIP }}\right)$ and consequently the $\eta_{\text {spectral }}$ because it accounts for the spectral region influenced by precipitable water. Therefore $S M R_{\text {bot }}^{\text {mid }}$ limits cannot be completely relaxed when a NIP is used as reference for the DNI, for example for outdoor rating of CPV. This issue is analyzed in detail in the next section. In summary, estimating $\mathrm{SMR}_{\text {mid }}^{\text {top }}$ in conjunction with the DNI from a pyrheliometer is enough to determine the solar cell photocurrent for the LM GalnP/GalnAs/Ge 
technology but not to evaluate $\eta_{\text {spectral }}$ and the performance of a CPV system. Consequently, SMR $\mathrm{R}_{\text {bot }}^{\text {mid }}$ must be also monitored and filter limits must be studied.

\subsection{Spectral efficiency and SMRs}

The spectral efficiency $\eta_{\text {spectral, }}$ as defined in Equation (8), quantifies the lack of proportionality between DNI and the current generated by a MJ solar cell due to spectral mismatch. Figure 5 displays $\eta_{\text {spectral }}$ calculated using equivalent irradiances from component cells of LM GalnP/GalnAs/Ge technology and DNI measured in Madrid in 2013 without any DNI filtering. $\eta_{\text {spectral }}$ ranges from 0.2 to values slightly higher than one where one means the same subcell current balance as at the reference spectrum AM1.5D-G173-03. The lowest values of $\eta_{\text {spectral }}$ take place when $A M$ is very high, i.e., at sunset and sunrise. As previously mentioned, it should be noticed that $\eta_{\text {spectral }}$ values higher than one indicate that the MJ solar cell produces more current than it was expected by the DNI measured with the pyrheliometer. For the case of LM GalnP/GalnAs/Ge technology, this happens when $S M R_{\text {mid }}^{\text {top }}$ is close to one and both, top and middle subcell regions, have higher irradiances than the reference while the bottom region irradiance is lower. This usually happens when the atmosphere has high water content (PW higher than the reference value $1.42 \mathrm{~cm}$ ), causing a DNI decrease than mainly affects the bottom subcell region.
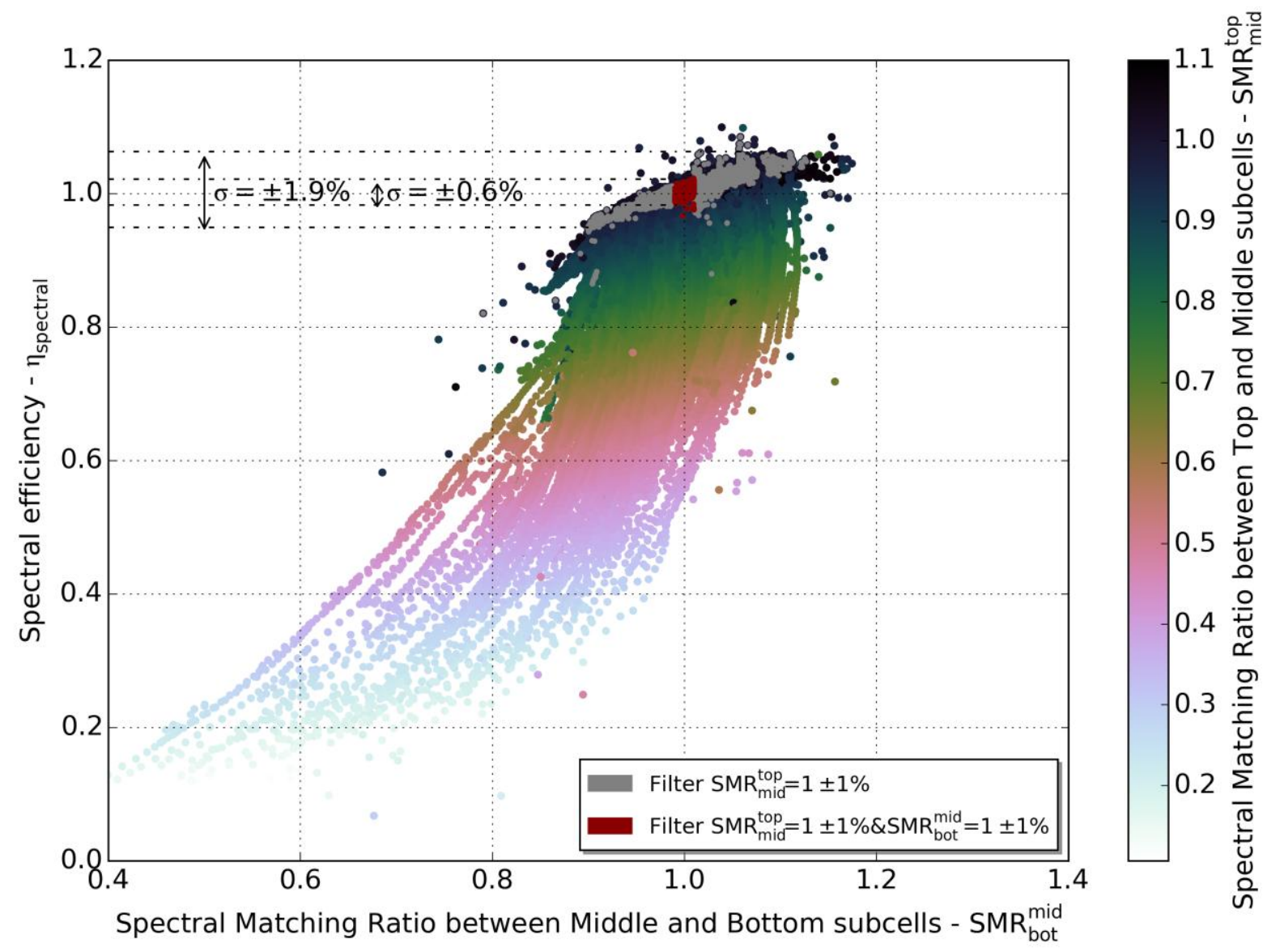

Figure 5. Distribution of spectral efficiency $\eta_{\text {spectral }}$ for different values of spectral matching ratios $S M R_{\text {mid }}^{\text {top }}$ and $S M R_{\text {bot }}^{\text {mid }}$ in Madrid in 2013 (sample period of one minute). If filter $S M R_{\text {mid }}^{\text {top }}=1 \pm 1 \%$ is applied (grey dots), it limits $\eta_{\text {spectral }}$ to $1 \pm 2.0 \%$. If the condition $S M R_{\text {bot }}^{\text {mid }}=1 \pm 1 \%$ is added (red dots), the dispersion of $\eta_{\text {spectral }}$ is reduced to $\pm 0.6 \%$. No DNI filters are applied, but all the filtered samples meet $\mathrm{DNI}>700 \mathrm{~W} \cdot \mathrm{m}^{-2}$. 
When the condition $\mathrm{SMR}_{\text {mid }}^{\text {top }}=1 \pm 1 \%$ is used to filter data, the collection of spectra is substantially reduced (only $7.6 \%$ of the spectra passes the filter) and $\eta_{\text {spectral }}$ is limited to $1 \pm 1.9 \%$. Those spectra are represented by gray points in Figure 5 . If $S M R_{\text {mid }}^{\text {top }}$ fully defined a solar spectrum for the MJ solar cell, every selected spectrum would have $\eta_{\text {spectral }}=1$. However, this is not the case because $\mathrm{SMR}_{\text {mid }}^{\text {top }}$ only takes into account the wavelength regions that top and middle subcells can detect. In order to take into consideration also the spectral region related to the bottom subcell, $\mathrm{SMR}_{\mathrm{bot}}^{\mathrm{mid}}$ range is also limited to $1 \pm 1 \%$ and represented in red dots. This leads to a significant reduction in the dispersion of $\eta_{\text {spectral }}(1 \pm 0.6 \%)$.

Figure 5 also unveils a remarkable linear correlation $\left(R^{2}=0.86\right)$ between $\eta_{\text {spectral }}$ and $S M R_{\text {bot }}^{\text {mid }}$ for $\mathrm{SMR}_{\text {mid }}^{\text {top }}$ values limited to $1 \pm 1 \%$, as shown in gray dataset. This is caused by the nature of the solar spectrum and how it is modified by water absorption. The plot shows clearly that, for this particular MJ solar cell technology, $\mathrm{SMR}_{\text {bot }}^{\text {mid }}$ should be limited to establish prevailing spectral conditions in CPV rating procedures, but not as much as $\mathrm{SMR}_{\text {mid }}^{\text {top }}$. Once $\mathrm{SMR}_{\text {mid }}^{\text {top }}$ is limited around one, $\mathrm{SMR}_{\mathrm{bot}}^{\mathrm{mid}}$ variations as high as $1 \pm 12 \%$ (grey dots) leads to spectral efficiency dispersions of only $\pm 1.9 \%$ (std. deviation), which mean values are within $\pm 6.0 \%$ with probability higher than $99 \%$. In other words, the sensibility of the spectral efficiency to $\mathrm{SMR}_{\text {bot }}^{\text {mid }}$ in Madrid for LM architecture is roughly one half the sensibility to $\mathrm{SMR}_{\text {mid }}^{\text {top }}$, so filter limits for $\mathrm{SMR}_{\text {bot }}^{\text {mid }}$ could be twice $\mathrm{SMR}_{\text {mid }}^{\text {top }}$ ones.

The main motivation to increase the limits of SMR filters is to increase the probability of occurrence of a certain prevailing spectral conditions, allowing filtered data under a wider range of other operating variables such as ambient temperature. However, it must be taken into account that, given a set of spectra data which corresponds to a period of operating conditions, the error in $\eta_{\text {spectral }}$ may depend less on the limit range for SMRs than in the average value of the SMRs for the data collection, which could be the dominant source of error with wider SMR filters. For instance, if $\mathrm{SMR}_{\mathrm{bot}}^{\mathrm{mid}}=1 \pm 5 \%$ is considered as filter condition, the impact on the rated value would be quite different if the average value of $\mathrm{SMR}_{\mathrm{bot}}^{\mathrm{mid}}$ for the data collection is 1.0 (no bias error) or 1.03 (bias error of $+3 \%)$. As a consequence, wider SMR filters should also include some consideration about the average value of the data collections. The Table 3 shows the dispersion of the spectral efficiency for different SMR filters, showing that the average value of $\eta_{\text {spectral }}$ is close to one regardless the width of the filters, under the condition of SMR averages close to one for the data population.

Table 3. Average values and dispersions of the spectral efficiency $\eta_{\text {spectral }}$ for different SMR filters around one. Filters have been applied to one year of minute-resolved SMR measurements in Madrid. Average SMR values are also indicated in brackets for the population of data, showing they are very close to one to avoid causing bias errors in $\eta_{\text {spectral }}$

\begin{tabular}{|c|c|c|}
\hline Filtering condition & $\mathrm{SMR}_{\mathrm{mid}}^{\mathrm{top}}=1 \pm \varepsilon \%$ & $\begin{array}{c}\mathrm{SMR}_{\mathrm{mid}}^{\mathrm{top}}=1 \pm \varepsilon \% \& \\
\mathrm{SMR}_{\mathrm{bot}}^{\mathrm{mid}}=1 \pm \varepsilon \%\end{array}$ \\
\hline$\varepsilon=1 \%$ for $\mathrm{SMRs}$ & $\begin{array}{c}\text { Avg }=1.006 \\
\text { Std }=1.9 \% \\
\left.\text { [Average } \mathrm{SMR}_{\text {mid }}^{\text {top }}=1.000\right]\end{array}$ & $\begin{array}{c}\mathrm{Avg}=1.002 \\
\mathrm{Std}=0.6 \% \\
{\left[\text { Average } \mathrm{SMR}_{\mathrm{mid}}^{\mathrm{top}}=1.000\right]} \\
{\left[\text { Average } \mathrm{SMR}_{\mathrm{bot}}^{\text {mid }}=1.001\right]}\end{array}$ \\
\hline$\varepsilon=2.5 \%$ for SMRs & $\begin{array}{c}\mathrm{Avg}=1.005 \\
\mathrm{Std}=2.1 \% \\
{\left[\text { Average } \mathrm{SMR}_{\text {mid }}^{\text {top }}=1.001\right]}\end{array}$ & $\begin{array}{c}\mathrm{Avg}=1.002 \\
\mathrm{Std}=1.06 \% \\
{\left[\text { Average } \mathrm{SMR}_{\mathrm{mid}}^{\mathrm{top}}=1.002\right]} \\
{\left[\text { Average } \mathrm{SMR}_{\mathrm{bot}}^{\mathrm{mid}}=1.003\right]}\end{array}$ \\
\hline $\begin{array}{c}\varepsilon=1 \% \text { for } \mathrm{SMR}_{\mathrm{mid}}^{\mathrm{top}} \\
\varepsilon=2.5 \% \text { for } \mathrm{SMR}_{\text {bot }}^{\mathrm{mid}}\end{array}$ & $\begin{array}{l}\text { Avg }=1.006 \\
\text { Std }=1.9 \%\end{array}$ & $\begin{aligned} \text { Avg } & =1.002 \\
\text { Std } & =0.9 \%\end{aligned}$ \\
\hline
\end{tabular}




\begin{tabular}{|l|l|l|}
\hline & [Average $\left.\mathrm{SMR}_{\mathrm{mid}}^{\mathrm{top}}=1.000\right]$ & $\begin{array}{l}\left.\text { [Average } \mathrm{SMR}_{\mathrm{mid}}^{\mathrm{top}}=1.000\right] \\
\left.\text { [Average } \mathrm{SMR}_{\mathrm{bot}}^{\text {mid }}=1.003\right]\end{array}$ \\
\hline
\end{tabular}

\subsection{CPV power rating: spectral filtering by means of SMRs}

Up to now, the analysis carried out has been focused on the relationship between a bare MJ solar cell and the component cells of the same technology based on the fact that both, the MJ solar cell and the set of component cells, have identical relative spectral response. However, a CPV system is composed not only of MJ solar cells, but also optics. Hence, spectral effects caused by the optics [31], [32] (chromatic aberration, material transmittance) may play an important role that cannot be neglected. Additionally, there are temperature effects that also have a significant impact. In the first place, the operating cell temperature of the MJ solar cells will be different than that of the component cells, which affects the spectral response of the devices. In the second place, the lens temperature may significantly affect its effective focal distance and color mixing [33]-[36] which also affects the light spectrum over the cell. Obviously the impact of these issues depends on the type of CPV module, mainly its optical design (refractive vs. reflective, number of stages, geometrical concentration, etc).

Taking into account that SMRs are obtained by means of bare component cells and the effects described above, the condition $\mathrm{SMR}_{\text {mid }}^{\text {top }}=1$ and $\mathrm{SMR}_{\text {bot }}^{\text {mid }}=1$ (the reference SMR condition) does not produce equivalent spectra to the reference one for a CPV module because the photocurrent balance may differ due to optical and temperature effects. But the question that we are trying to answer is whether that condition could ensure repeatable spectral conditions for the CPV module and consequently repeatable power rating of the CPV module under that condition. As seen before, the reference SMR condition leads to solar spectra that resemble very much the reference AM1.5DG173-03 if the requirement of DNI close to $900 \mathrm{~W} \cdot \mathrm{m}^{-2}$ is added, but not necessarily if the DNI range is wider.

For rating of CPV modules and systems, the approach currently used by several laboratories [29], [37] consists in keeping the pyrheliometer as reference instrument to account for the incoming DNI and use the component cells to determine prevailing spectral conditions by filtering $\mathrm{SMR}_{\mathrm{mid}}^{\mathrm{top}}$ and $\mathrm{SMR}_{\text {bot }}^{\text {mid }}$ values around one. This approach is also currently included in the draft of the IEC 62670-3 standard [30] focused on the performance measurements and power rating of CPV modules.

The analysis we will show is based on a $15 \mathrm{~kW}$ CPV array installed in Madrid, using two-stage refractive optics and 3J solar cells working above 800X [38]. First, we will focus on the power rating of the array at Concentrator Standard Operating Conditions (CSOC) [39]. The objective is to rate the power of the array at CSOC in the short term, carried out for only a few days after its installation and set-up. Figure 6 shows the current at the maximum power point normalized by DNI for a couple of days with different filters applied. The current at maximum power point has been represented instead of power itself to avoid further data correction due to temperature issues. It must not be forgotten that the spectral distribution of the irradiance at the entrance aperture of the CPV modules will influence the fill factor FF and thus the power of the MJ solar [9]. The current at maximum power point accounts at least partially for this effect and is much less sensitive to temperature variations than voltage and consequently power. Nevertheless, for the example case detailed above, relatively constant cell temperatures are expected for the filtered data which obtained in steady state conditions and with relatively constant ambient temperature and wind conditions during the two days, so power will be also analyzed for comparison. 


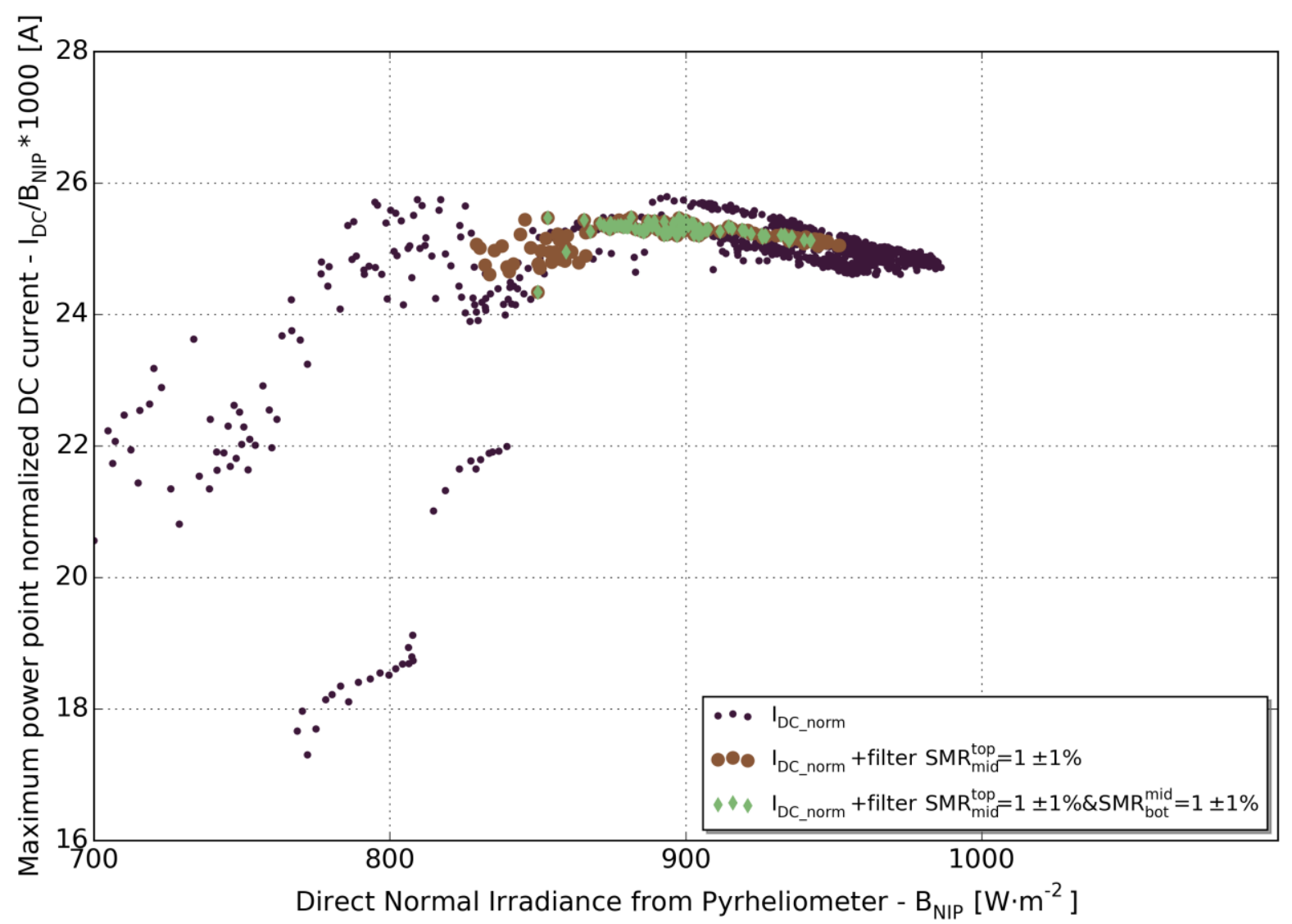

Figure 6. Normalized DC current at the maximum power point of a CPV system $I_{D C} / B_{N I P}$ as a function of the direct normal irradiance (DNI) measured with a pyrheliometer $\mathrm{B}_{\mathrm{NIP}}$. Two days of data are shown. Black dots correspond to the clear condition filter (DNI>700 $\left.\mathbf{W} \cdot \mathrm{m}^{-2}\right)$. Brown triangles represent the addition of the condition $S M R_{\text {mid }}^{\text {top }}=1 \pm 1 \%$. The requirement $S M R_{b o t}^{\text {mid }}=1 \pm 1 \%$ has been added for green marks.

Table 4 collects the average values and their dispersion obtained for the rated current and power at the maximum power point. Both Figure 6 and Table 4 show the high dispersion of rated values when the only condition of clear sky (DNI $>700 \mathrm{~W} \cdot \mathrm{m}^{-2}$ ) is applied (purple dots). If the spectral filters are added, based on SMRs obtained from spectroheliometer data, standard deviation are decreased to values as low as $0.7 \%$ and $0.2 \%$ for one (brown circles) or two (green markers) SMR conditions of $\pm 1 \%$ respectively. Even for the case of SMR filters of $\pm 2.5 \%$, the dispersion achieved in the rated current is well below $\pm 1 \%$. Regarding power dispersion, results are very similar, proving that FF variations caused by spectral changes mostly effect the current at maximum power.

Table 4. Results of a short-term ( 2 days of data measurement) rating of a $15 \mathrm{kWp}$ CPV array based on a two stage refractive optics working above 800X installed in Madrid. Both average value and standard deviation for the normalized current and power at the maximum power point $(A / W)$ are detailed for each filtering condition.

\begin{tabular}{|c|c|c|c|c|c|c|}
\hline Filtering condition & \multicolumn{2}{|c|}{$\begin{array}{c}\text { DNI > } 700 \\
\text { No SMR filt. }\end{array}$} & \multicolumn{2}{|c|}{$\begin{array}{c}\mathrm{DNI}>700 \\
\mathrm{SMR}_{\mathrm{mid}}^{\mathrm{top}}=1 \pm \varepsilon \%\end{array}$} & \multicolumn{2}{|c|}{$\begin{array}{c}\mathrm{DNI}>700 \\
\mathrm{SMR}_{\text {mid }}^{\text {top }}=1 \pm \varepsilon \% \\
\mathrm{SMR}_{\mathrm{bot}}^{\text {mid }}=1 \pm \varepsilon \%\end{array}$} \\
\hline $\begin{array}{c}\varepsilon=1 \% \text { for SMRs } \\
\text { when applicable }\end{array}$ & $\begin{array}{c}I_{D C \_n o r m} \\
\text { Avg }=24.53 \\
\text { Std }= \pm 7.5 \%\end{array}$ & $\begin{array}{c}P_{\mathrm{DC} \_ \text {norm }} \\
\mathrm{Avg}=13721 \\
\mathrm{Std}= \pm 8.0 \%\end{array}$ & $\begin{array}{c}I_{D C \_n o r m} \\
\text { Avg }=25.21 \\
\text { Std }= \pm 0.7 \%\end{array}$ & 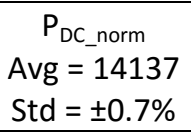 & $\begin{array}{c}I_{D C \_n o r m} \\
A v g=25.32 \\
S t d= \pm 0.2 \%\end{array}$ & $\begin{array}{c}P_{D C \_n o r m} \\
\text { Avg }=14209 \\
\text { Std }= \pm 0.3 \%\end{array}$ \\
\hline
\end{tabular}




\begin{tabular}{|c|c|c|c|c|}
\hline $\begin{array}{l}\varepsilon=2.5 \% \text { for SMRs } \\
\text { when applicable }\end{array}$ & $\begin{array}{c}\mathrm{I}_{\mathrm{DC} \_ \text {norm }} \\
\text { Avg }=25.18 \\
\mathrm{Std}= \pm 0.8 \%\end{array}$ & $\begin{array}{c}P_{D C_{\text {_norm }}} \\
\text { Avg }=14119 \\
\text { Std }= \pm 0.8 \%\end{array}$ & $\begin{array}{c}\mathrm{I}_{\mathrm{DC} \_ \text {norm }} \\
\text { Avg }=25.28 \\
\text { Std }= \pm 0.6 \%\end{array}$ & $\begin{array}{c}P_{D C_{n} \text { norm }} \\
\text { Avg }=14165 \\
\text { Std }= \pm 0.6 \%\end{array}$ \\
\hline
\end{tabular}

The same analysis has been carried out over a longer period to better show the strength of the SMR filters. Results of one year data are shown in Figure 7 and Table 5. It should be noted that data are affected by the soiling in the array, since array cleaning happened only through natural washing by rain, which may limit the evolution of the dispersion values. Despite this limitation, the reduction in the dispersion of the rated values when using SMR filters is clearly observable in Figure 7.

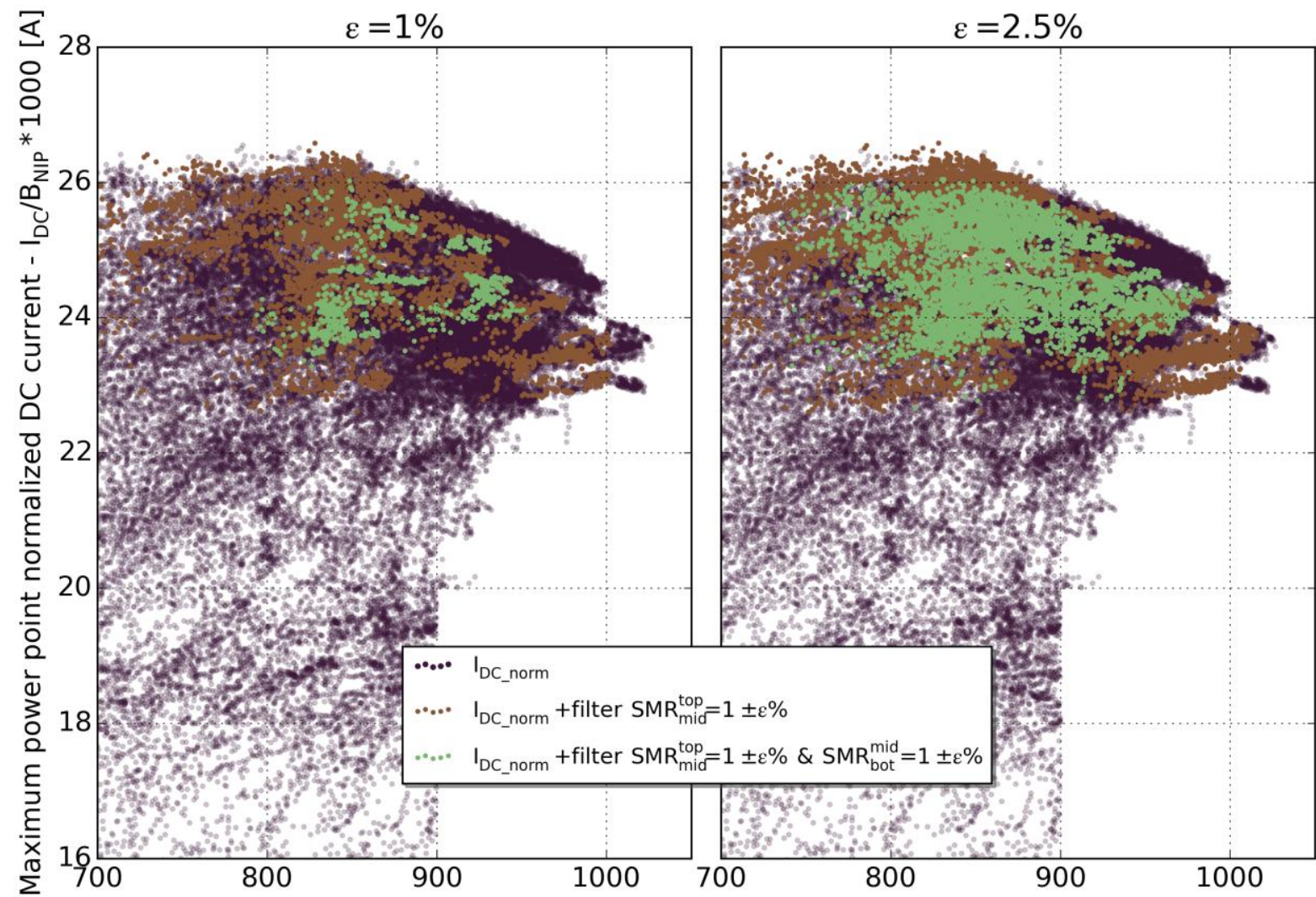

Direct Normal Irradiance from Pyrheliometer $-\mathrm{B}_{\mathrm{NIP}}\left[\mathrm{W} \cdot \mathrm{m}^{-2}\right]$

Figure 7. Normalized DC current at the maximum power point of a CPV system $I_{D C} / B_{N I P}$ as a function of the direct normal irradiance (DNI) measured with a pyrheliometer $B_{\mathrm{NIP}}$. One year of data are shown. Purple dots correspond to the clear condition filter (DNI $>700 \mathrm{~W} \cdot \mathrm{m}^{-2}$ ). Brown dots represent data filtered adding the condition $S M R_{\text {mid }}^{\text {top }}=1 \pm 1 \%$ in the left and $S M R_{\text {mid }}^{\text {top }}=1 \pm 2.5 \%$ in the right. The requirement $S M R_{\text {bot }}^{\text {mid }}=1 \pm 1 \%$ or $1 \pm 2.5 \%$ has also been added in green dots.

Table 5. Results of a long-term (1 year of data measurement) rating of a $15 \mathrm{kWp} \mathrm{CPV} \mathrm{array} \mathrm{based}$ on a two stage refractive optics working above $800 \mathrm{X}$ installed in Madrid. Both average value and standard deviation for the normalized current and power at the maximum power point $(A / W)$ are detailed for each filtering condition.

\begin{tabular}{|c|c|c|c|}
\hline \multirow{3}{*}{ Filtering condition } & DNI $>700$ & $\mathrm{DNI}>700$ & $\mathrm{DNI}>700$ \\
& No SMR filt. & $\mathrm{SMR}_{\text {mid }}^{\text {top }}=1 \pm \varepsilon \%$ & $\mathrm{SMR}_{\text {mid }}^{\text {top }}=1 \pm \varepsilon \%$ \\
$\mathrm{SMR}_{\text {bot }}^{\text {mid }}=1 \pm \varepsilon \%$
\end{tabular}




\begin{tabular}{|c|c|c|c|c|c|c|}
\hline $\begin{array}{c}\varepsilon=1 \% \text { for SMRs } \\
\text { when applicable }\end{array}$ & IDC_norm & PDC_norm & $\begin{array}{c}I_{D C \text { norm }} \\
\text { Avg }=24.69 \\
\text { Std }= \pm 3.6 \%\end{array}$ & $\begin{array}{c}P_{\text {DC_norm }} \\
\text { Avg }=13921 \\
\text { Std }= \pm 3.5 \%\end{array}$ & $\begin{array}{c}\mathrm{I}_{\mathrm{DC} \text { norm }} \\
\mathrm{Avg}=24.46 \\
\mathrm{Std}= \pm 2.4 \%\end{array}$ & $\begin{array}{c}P_{D C \text { norm }} \\
\text { Avg }=13847 \\
\text { Std }= \pm 3.3 \%\end{array}$ \\
\hline $\begin{array}{l}\varepsilon=2.5 \% \text { for } S M R s \\
\text { when applicable }\end{array}$ & $\begin{array}{l}\mathrm{Avg}=23.20 \\
\mathrm{Std}= \pm 12.6 \%\end{array}$ & $\begin{array}{l}\mathrm{Avg}=13046 \\
\mathrm{Std}= \pm 12.9 \%\end{array}$ & $\begin{array}{c}I_{D C \_n o r m} \\
A v g=24.70 \\
S t d= \pm 3.5 \%\end{array}$ & $\begin{array}{c}P_{D C \text { norm }} \\
\text { Avg }=13920 \\
\text { Std }= \pm 3.3 \%\end{array}$ & $\begin{array}{c}\mathrm{I}_{\mathrm{DC} \text { norm }} \\
\mathrm{Avg}=24.70 \\
\mathrm{Std}= \pm 2.7 \%\end{array}$ & $\begin{array}{c}P_{D C \text { norm }} \\
\text { Avg }=13919 \\
\text { Std }= \pm 2.9 \%\end{array}$ \\
\hline
\end{tabular}

\section{Spectral characterization of a place. Energy losses due to spectral variation}

Several authors have analyzed the effect of spectral variation on the annual current produced by a MJ solar cell in a particular location using some representative spectra [40], [41] or radiative models as MODTRAN [5], SPCTRAL2 [7], [42] or SMARTS [8], [43]-[45]. However all these models have the limitation that they use as inputs the atmospheric parameters whose measurement is complex and commonly require expensive instrumentation. As has been remarked before, the spectral efficiency $\eta_{\text {spectral }}$ is a simpler approach presented in this work which also allows for the validation of the aforementioned models.

The spectral efficiency $\eta_{\text {spectral }}$ accounts for the photocurrent losses caused by the differences between the spectral distribution of the DNI at every moment and the reference spectrum. When the spectral efficiency is integrated over a period of time $t$, an estimation of the collected energy taking into account spectral mismatch, $\eta_{\text {spectral,t }}$ can be calculated as:

$$
\eta_{\text {spectral }}=\frac{\int_{t} B_{M J}(t) d t}{\int_{t} B_{N I P}(t) d t}
$$

The evolution of the spectral efficiency throughout a sunny day was presented in Figure 4. The gray area represents the difference between the daily integrated values of DNI and spectrally corrected DNI $\left(B_{M J}\right)$ respectively. The ratio between both integrated values represents the losses in the current of a MJ solar cell due to spectral variation over a certain period of time, a day in this particular case. For example, for the day shown in Figure $4, \eta_{\text {spectral,day }}$ is $94.2 \%$, so the current losses due to changes in the solar spectrum, compared to the reference spectrum AM1.5D-173-03, are 5.8\%.

The atmosphere changes throughout the day and the year, usually showing periodical patterns caused by local characteristics. Monthly averages of $\eta_{\text {spectral }}$ can be obtained for a certain location and solar cell technology if enough experimental data is available. This information can be applied to CPV modeling and energy prediction for a specific location [7], [8], [40]-[43], and it could be used together with the information provided in radiation databases to forecast the energy harvested by a CPV system. Figure 8 shows the spectral efficiency in Madrid integrated over every month for three years (2012-2014) and Table 6 presents these values, including the annually-integrated value per year. 


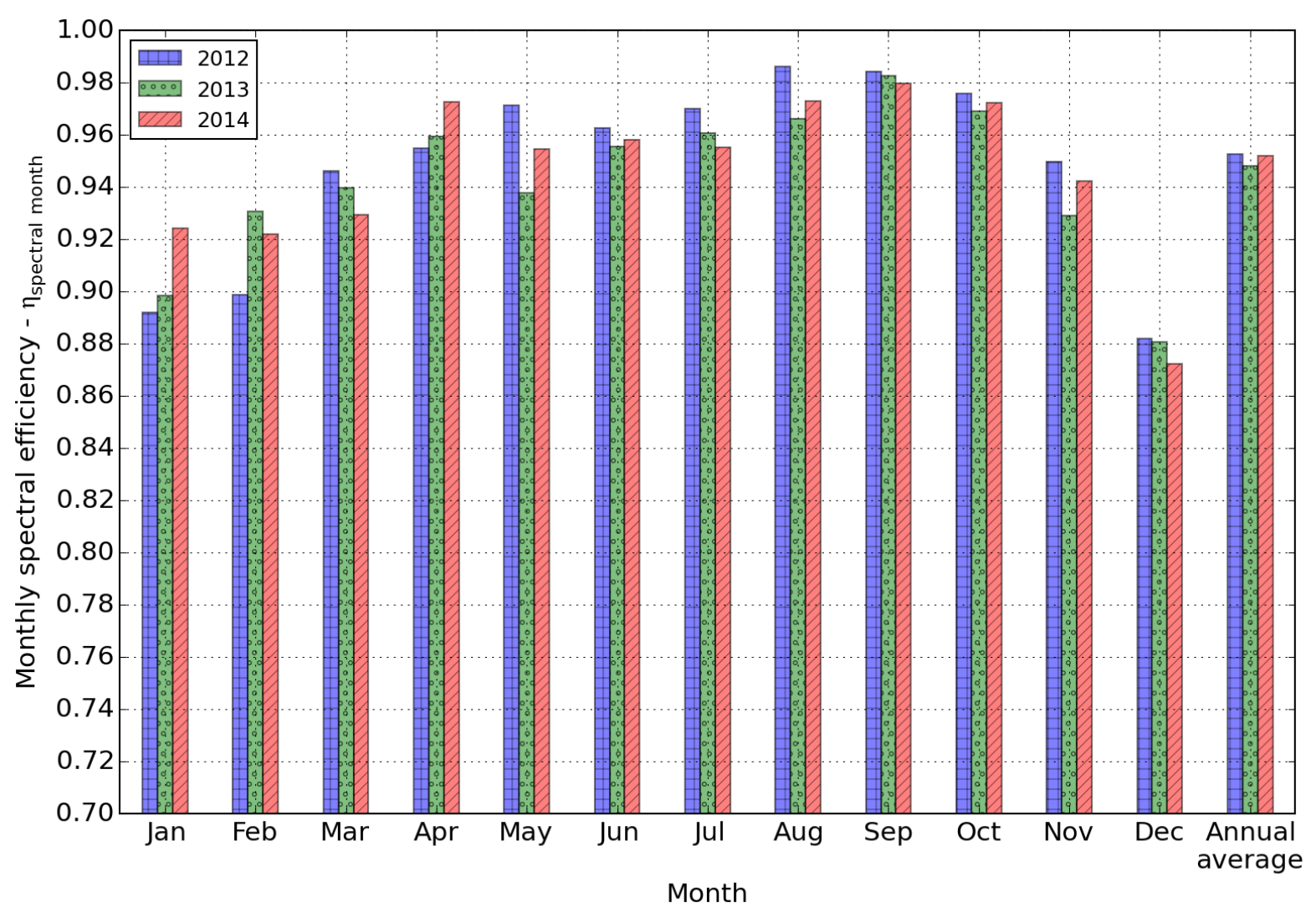

Figure 8. Evolution of the spectral efficiency integrated over every month $\eta_{\text {spectral,month }}$ and the annually-integrated values for the years 2012-2014 in Madrid. $\eta_{\text {spectral,month }}$ gives an idea of the expected current losses due to spectral mismatch for a lattice-matched (LM) GalnP/GalnAs/Ge triple-junction (3J) solar cell.

The annual average for the three years is 0.95 , so around $5 \%$ of current losses in that particular MJ solar cell technology are caused by spectral mismatch. For the complete CPV system the change in the transmittance of the optics may increase or reduce these losses.

Table 6. Spectral efficiency integrated over every month $\eta_{\text {spectral, month }}$ and annually-integrated value for the years 2012-2014 in Madrid.

\begin{tabular}{|l|l|l|l|l|l|l|l|l|l|l|l|l|l|}
\hline & Jan & Feb & Mar & Apr & May & Jun & Jul & Aug & Sep & Oct & Nov & Dec & Year \\
\hline 2012 & 0.89 & 0.90 & 0.95 & 0.95 & 0.97 & 0.96 & 0.97 & 0.99 & 0.98 & 0.98 & 0.95 & 0.88 & 0.95 \\
\hline 2013 & 0.90 & 0.93 & 0.94 & 0.96 & 0.94 & 0.96 & 0.96 & 0.97 & 0.98 & 0.97 & 0.93 & 0.88 & 0.95 \\
\hline 2014 & 0.92 & 0.92 & 0.93 & 0.97 & 0.95 & 0.96 & 0.95 & 0.97 & 0.98 & 0.97 & 0.94 & 0.87 & 0.95 \\
\hline
\end{tabular}

\subsection{Annual energy distribution versus SMR}

Besides the annual and monthly integrated spectral efficiency for a particular location, it is also useful to define a energetic representative spectrum for a place. This spectrum could be used to optimize a CPV module, for example, by tuning the photocurrents [42], [44], [45] generated by every subcell or by adjusting the optical design [33]. The optimum photocurrent ratios I ratios $_{\text {that maximize }}$ energy harvesting at a certain location may not be the ones that maximize the current of the device under AM1.5D-G173-03, represented by SMR values equal to one. 
Strongly influenced by local climate, the majority of the energy may be found at SMR values different from one, e.g., at high altitude locations with clear sky the most probable situation is $\mathrm{SMR}_{\text {mid }}^{\text {top }}>1$. Therefore, the middle subcell would limit the current of the device most of the time. As a consequence, the $\mathrm{I}_{\text {ratio }^{\text {mid }}}$ mop $_{\text {ref }}$ value that maximizes the annually harvested energy for that particular location would be lower than one.

The representative SMRs for a given location can be calculated by integrating the SMRs weighted by the direct normal irradiation $\mathrm{E}_{\mathrm{DNI}}$, over the whole year

$$
\overline{\operatorname{SMR}}_{\text {subcell }_{j}}^{\text {subcell }_{\mathrm{i}}}=\frac{\int_{\text {year }} \mathrm{SMR}_{\text {subcellj }}^{\text {subcell }}(t) \cdot \mathrm{E}_{\mathrm{DNI}}(t) \mathrm{dt}}{\int_{\text {year }} \mathrm{E}_{\mathrm{DNI}}(t) \mathrm{dt}}
$$

The distribution of the annual direct normal irradiation as a function of $\mathrm{SMR}_{\text {mid }}^{\text {top }}$ and $\mathrm{SMR}_{\mathrm{bot}}^{\mathrm{mid}}$ is shown in Figure 9 for Madrid in 2013 with minute resolution. Both SMRs define a mesh whose size is $100 \times 100$ bins with a resolution of $0.005 \times 0.005$. The false color map represents an indication of the direct normal irradiation that is received in Madrid for every combination of SMR values.

The dot in Figure 9 indicates the SMR barycenter, that is, the weighted average of the direct normal irradiation in spectral coordinates $\left(\overline{\mathrm{SMR}}_{\text {mid }}^{\text {top }}\right.$ and $\left.\overline{\mathrm{SMR}}_{\text {bot }}^{\text {mid }}\right)$ which are respectively 0.96 and 1.00 . It must be pointed out that both values are very close or equal to one, which indicates that the reference spectrum AM1.5D-G173-03 is quite suitable to optimize a LM GalnP/GalnAs/Ge MJ solar cell for the climate of Madrid. 


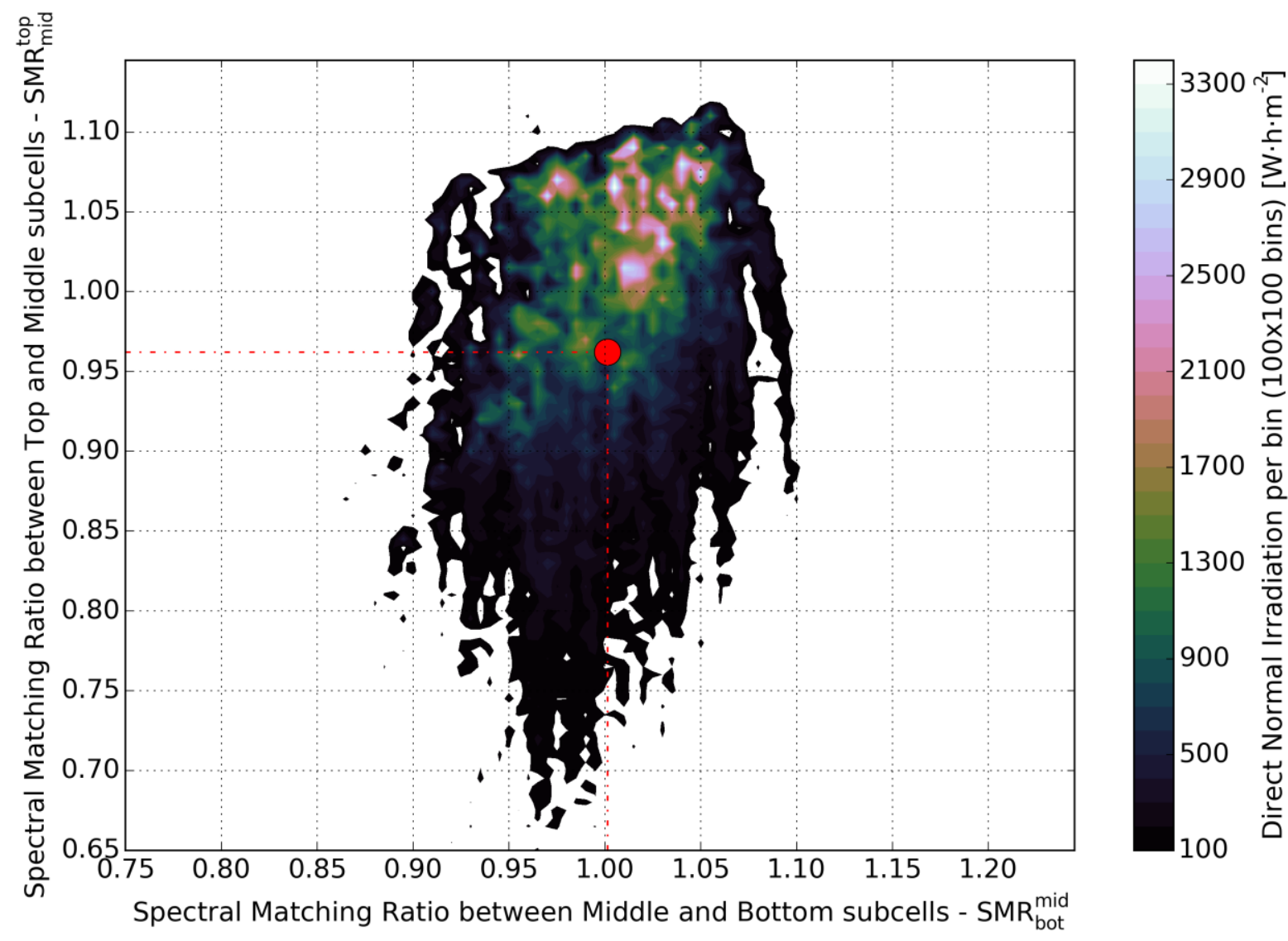

Figure 9. Spectral distribution of direct normal irradiation in Madrid throughout 2013 expressed as a function of spectral matching ratios $\left(S M R_{\text {mid }}^{\text {top }}\right.$ and $\left.S M R_{b o t}^{\text {mid }}\right)$. The red dot indicates the barycenter, i.e. the energy weighted SMR values that maximizes the annually integrated spectral efficiency.

\subsection{Spectral optimization of a MJ solar cell for a particular location}

The most direct way to optimize a MJ solar cell consists of tuning the subcell bandgaps so that the current ratio $I_{\text {ratio }_{\text {subcell }}}$ subefl $_{\text {ref }}$ equals one under the reference spectrum. Alternatively, some authors [42]-[45] have used a set of spectra representative for a particular location to determine the ratio that maximize the current produced by that MJ solar cell throughout the year. They used modeled spectra based on radiative models feed with atmospheric parameters. Instead, we propose here to use measurements obtained with a spectroheliometer to determine the optimum $I_{\text {ratio }_{\text {subcell }} \text { subf }_{\text {ref }}}$.

The annually energy weighted $\overline{\mathrm{SMR}}_{\text {mid }}^{\text {top }}$ and $\overline{\mathrm{SMR}}_{\text {bot }}^{\text {mid }}$ can be used to estimate the $\mathrm{I}_{\text {ratio }}$ subcell $_{\mathrm{i}}$ subcell $_{\mathrm{j}_{\text {ref }}}$ that would maximize the current generated by the corresponding MJ solar cell technology throughout the year in a certain location. The set of $\overline{\mathrm{SMR}}_{\text {subcellj }}^{\text {subcell }}$ can be calculated using the definition of SMR

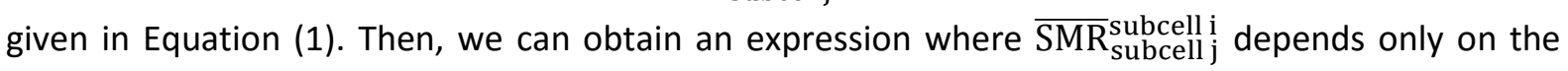
annually energy weighted current ratio between subcell $i$ and $j\left(\overline{I_{\text {ratio }}}\right.$ subcell $i$ ) and the current ratio of the same subcells under the reference spectrum ( $\mathrm{I}_{\text {ratio }}$ subcell $\left.\mathrm{i} \mathrm{j}_{\mathrm{ref}}\right)$, according to:

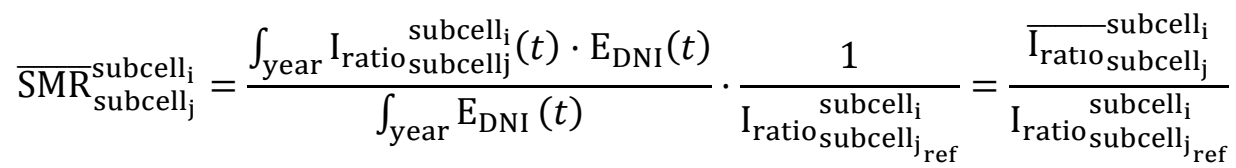


Maximizing the current generated annually in a particular place implies setting $\overline{\mathrm{I}_{\text {ratio }}}$ subcell $\mathrm{i}$ subcell $\mathrm{j}$ equal to one. Hence, the optimum value for the subcell photocurrent ratio under the reference spectrum for that particular location, $\mathrm{I}_{\text {ratio_optimum }}$ subcell $_{\mathrm{i}}$, is

$$
\mathrm{I}_{\text {ratio_optimum }}^{\text {subcell }_{\mathrm{i}}} \text { subcell }_{\mathrm{j}_{\text {ref }}}=\frac{1}{\overline{\mathrm{SMR}} \text { subcell }_{\text {subcell }_{j}}}
$$

This can be understood as follows. For the sake of clarity the discussion is based on the top and middle subcells photocurrent ratio but it will be equivalent for the middle and bottom. If for a certain location and MJ solar cell technology $\overline{\mathrm{SMR}}_{\text {mid }}^{\text {top }}$ is higher than one, it means that the direct normal irradiation is, in average, blue-shifted and the MJ current is most of the time limited by the middle subcell. In this situation it would be convenient to tune the $\mathrm{I}_{\text {ratio }}$ midref $_{\text {ref }}$ to a value lower than one so the time throughout the year when the middle subcell is limiting would be reduced.

This optimization of $I_{\text {ratio } \text { subcell }_{j_{\text {ref }}}}$ presented here ignores some aspects that should certainly be considered to optimize the energy annually harvested by a CPV system. Among them, the most important are the effects of temperature dependence of the optics transmittance [34]-[36] [46] and the impact of cell temperature on the spectral response [47]. Our approach to include both effects will be published in a following article.

A more complete analysis should also account for the effect of the optics on the spectral distribution on the MJ cell [46], the change on the transmittance due to temperature variations on the optics [34], [36] or the real operation cell temperature [47]. This study should be also extended to other cell MJ technologies, particularly those with very different subcells bandgaps or higher number of junctions.

\section{Conclusions}

A spectroheliometer composed of component cells has been presented as a simple and effective instrument to quantify the spectral variation of the DNI and its influence on MJ solar cells and CPV systems. This instrument provides experimental data to obtain the Spectral Matching Ratios (SMRs), a set of spectral indexes that quantifies any particular spectra by comparing it to a reference spectrum.

The first use of these SMR indexes is filtering of operating conditions, providing a simple way to determine prevailing spectral conditions by keeping SMR values around one. This approach has proved a significant reduction in the dispersion of the rated current of CPV cells, modules and systems based on MJ cells. The study of the site of Madrid has revealed the probability of the occurrence of the prevailing spectral conditions according the range of the SMR filters, which is one of the open questions in the CPV community. Ranges of $\pm 1 \%$ for the SMR filters showed dispersion values of the rated current at the maximum power point as low as $\pm 0.2 \%$ for a $15 \mathrm{kWp} \mathrm{CPV}$ array during a rating period of two clear-sky days, while simple clear sky condition of DNI higher than $700 \mathrm{~W} \cdot \mathrm{m}^{-2}$ leaded to dispersion values as high as $\pm 7 \%$. Higher ranges of SMRs $\pm 2.5 \%$ showed also very good results $( \pm 0.6 \%)$, with the clear advantage of a much higher probability of occurrence, but it should be accompanied of further conditions for the average SMRs of the population of data to avoid possible bias error. 
The spectrally corrected DNI concept has been presented in the paper to account for the spectral variations of the DNI. The derived spectral efficiency computes the losses associated to such spectral variations. Moreover, its integration over days, months or years for a specific site reveals the spectral losses to be expected in such site for a particular MJ technology, which can be used in the modeling and energy forecast of CPV systems.

A procedure for the spectral characterization of a particular site has been proposed in the paper based on SMR indexes. This information reveals how the annual energy weighted spectrum of the site compares to the reference spectrum and provides useful information for the optimization of a particular MJ technology for that site.

\section{Acknowledgements}

This work has been supported by the European Commission through the project SOPHIA (EU Ref. N: 262533) and by the Comunidad de Madrid through the program MADRID-PV-CM (S2013/MAE2780). Rubén Núñez is thankful to the Spanish Ministerio de Economía y Competitividad for his FPI grant.

This work made use of the Scipy stack [48], an open-source Python-based scientific computing environment. Some figures are using "cubehelix" color scheme [49], a black and white compatible color set.

\section{References}

[1] M. A. Green, K. Emery, Y. Hishikawa, W. Warta, and E. D. Dunlop, "Solar cell efficiency tables (version 46)," Prog. Photovolt. Res. Appl., vol. 23, no. 7, pp. 805-812, Jul. 2015.

[2] K. Emery, M. Meusel, R. Beckert, F. Dimroth, A. Bett, and W. Warta, "Procedures for evaluating multijunction concentrators," in Conference Record of the Twenty-Eighth IEEE Photovoltaic Specialists Conference, 2000, 2000, pp. 1126-1130.

[3] M. Muller, B. Marion, S. Kurtz, and J. Rodriguez, "An investigation into spectral parameters as they impact CPV module performance," in AIP Conference Proceedings, 2010, vol. 1277, p. 307.

[4] M. Muller, B. Marion, J. Rodriguez, and S. Kurtz, "Minimizing Variation In Outdoor CPV Power Ratings," in AIP Conference Proceedings, 2011, vol. 1407, pp. 336-340.

[5] K. M. Armijo, R. K. Harrison, B. H. King, and J. B. Martin, "Spectral derates phenomena of atmospheric components on multi-junction CPV technologies," in AIP Conference Proceedings, 2014, vol. 1616, pp. 264-271.

[6] C. A. Gueymard, "Parameterized transmittance model for direct beam and circumsolar spectral irradiance," Sol. Energy, vol. 71, no. 5, pp. 325-346, Nov. 2001.

[7] P. Faine, S. R. Kurtz, C. Riordan, and J. M. Olson, "The influence of spectral solar irradiance variations on the performance of selected single-junction and multijunction solar cells," Sol. Cells, vol. 31, no. 3, pp. 259-278, Jun. 1991.

[8] J. Jaus and C. A. Gueymard, "Generalized spectral performance evaluation of multijunction solar cells using a multicore, parallelized version of SMARTS," in AIP Conference Proceedings, 2012, vol. 1477, pp. 122-126.

[9] W. E. McMahon, K. E. Emery, D. J. Friedman, L. Ottoson, M. S. Young, J. S. Ward, C. M. Kramer, A. Duda, and S. Kurtz, "Fill factor as a probe of current-matching for GalnP2/GaAs tandem cells in a concentrator system during outdoor operation," Prog. Photovolt. Res. Appl., vol. 16, no. 3, pp. 213-224, 2008.

[10] M. Meusel, R. Adelhelm, F. Dimroth, A. W. Bett, and W. Warta, "Spectral mismatch correction and spectrometric characterization of monolithic III-V multi-junction solar cells," Prog. Photovolt. Res. Appl., vol. 10, no. 4, pp. 243-255, 2002. 
[11] G. Peharz, G. Siefer, and A. W. Bett, "A simple method for quantifying spectral impacts on multi-junction solar cells," Sol. Energy, vol. 83, no. 9, pp. 1588-1598, Sep. 2009.

[12] C. Domínguez, S. Askins, I. Antón, and G. Sala, "Characterization of five CPV module technologies with the Helios 3198 Solar Simulator," in 34th IEEE Photovoltaic Specialists Conference, Philadelphia, USA, 2009, pp. 1004-1008.

[13] C. Domínguez, I. Antón, G. Sala, and S. Askins, "Current-matching estimation for multijunction cells within a CPV module by means of component cells: Current-matching estimation for MJ cells within a concentrator," Prog. Photovolt. Res. Appl., vol. 21, no. 7, pp. 1478-1488, Nov. 2013.

[14] C. Cornaro and A. Andreotti, "Influence of Average Photon Energy index on solar irradiance characteristics and outdoor performance of photovoltaic modules," Prog. Photovolt. Res. Appl., vol. 21, no. 5, pp. 996-1003, 2013.

[15] R. Gottschalg, T. R. Betts, D. G. Infield, and M. J. Kearney, "The effect of spectral variations on the performance parameters of single and double junction amorphous silicon solar cells," Sol. Energy Mater. Sol. Cells, vol. 85, no. 3, pp. 415-428, Jan. 2005.

[16] T. Ishii, K. Otani, T. Takashima, and Y. Xue, "Solar spectral influence on the performance of photovoltaic (PV) modules under fine weather and cloudy weather conditions," Prog. Photovolt. Res. Appl., vol. 21, no. 4, pp. 481-489, 2013.

[17] F. Kasten and A. T. Young, "Revised optical air mass tables and approximation formula," Appl. Opt., vol. 28, no. 22, pp. 4735-4738, Nov. 1989.

[18] K. Emery, J. Delcueto, and W. Zaaiman, "Spectral corrections based on optical air mass," in Conference Record of the Twenty-Ninth IEEE Photovoltaic Specialists Conference, 2002, 2002, pp. $1725-1728$.

[19] I. Antón, M. Martínez, F. Rubio, R. Núñez, R. Herrero, C. Domínguez, M. Victoria, S. Askins, and G. Sala, "Power rating of CPV systems based on spectrally corrected DNI," AIP Conf. Proc., vol. 1477, no. 1, p. 331, 2012.

[20] B. N. Holben, T. F. Eck, I. Slutsker, D. Tanre, J. P. Buis, A. Setzer, E. Vermote, J. A. Reagan, Y. J. Kaufman, and T. Nakajima, "AERONET-A federated instrument network and data archive for aerosol characterization," Remote Sens. Environ., vol. 66, no. 1, pp. 1-16, 1998.

[21] R. W. Mueller, K. F. Dagestad, P. Ineichen, M. Schroedter-Homscheidt, S. Cros, D. Dumortier, R. Kuhlemann, J. A. Olseth, G. Piernavieja, C. Reise, L. Wald, and D. Heinemann, "Rethinking satellite-based solar irradiance modelling: The SOLIS clear-sky module," Remote Sens. Environ., vol. 91, no. 2, pp. 160-174, May 2004.

[22] P. A. Hubanks, M. D. King, S. Platnick, and R. Pincus, "MODIS atmosphere L3 gridded product algorithm theoretical basis document," NASA Goddard Space Flight Cent., Greenbelt, MD, 2008.

[23] "ASTM G173 standard tables for reference solar spectral irradiances," vol. AM15D.

[24] "IEC 60904-7 Computation of the spectral mismatch correction for measurements of photovoltaic devices," IEC, International Electrotechnical Commission, Geneva, 2008.

[25] R. Núñez, I. Antón, S. Askins, and G. Sala, "Atmospheric parameters, spectral indexes and their relation to CPV spectral performance," in AIP Conference Proceedings, 2014, vol. 1616, pp. 290-293.

[26] JCGM, "Evaluation of measurement data - Guide to the Expression of Uncertainty in Measurement (GUM)," BIPM, 2008.

[27] C. Domínguez, S. Askins, I. Antón, and G. Sala, "Indoor characterization of CPV modules using the Helios 3198 solar simulator," in 24th European Photovoltaic Solar Energy Conference and Exhibition, Hamburgo, Alemania, 2009, pp. 165-169.

[28] M. Muller, S. Kurtz, M. Steiner, and G. Siefer, "Translating outdoor CPV I-V measurements to a CSTC power rating and the associated uncertainty," Prog. Photovolt. Res. Appl., p. n/a-n/a, Mar. 2015. 
[29] G. Siefer, M. Steiner, M. Baudrit, C. Dominguez, I. Antón, R. Nuñez, F. Roca, P. M. Pugliatti, A. D. Stefano, R. Kenny, and P. Morabito, "SOPHIA CPV module round robin: Power rating at CSOC," in AIP Conference Proceedings, 2014, vol. 1616, pp. 167-172.

[30] IEC committee, "IEC 62670-3 - CONCENTRATOR PHOTOVOLTAIC (CPV) PERFORMANCE TESTING Part 3 - Performance measurements and power rating (Draft)," IEC, 2010.

[31] E. Lorenzo, "Chromatic aberration effect on solar energy systems using Fresnel lenses," Appl. Opt., vol. 20, no. 21, pp. 3729-3732, Nov. 1981.

[32] H. P. Annen, L. Fu, R. Leutz, L. González, and J. Mbakop, "Direct comparison of polymethylmetacrylate (PMMA) and silicone-on-glass (SOG) for Fresnel lenses in concentrating photovoltaics (CPV)," in SPIE Solar Energy+ Technology, 2011, pp. 811204-811204.

[33] M. Victoria, S. Askins, R. Nuñez, C. Domínguez, R. Herrero, I. Antón, G. Sala, and J. M. Ruíz, "Tuning the current ratio of a CPV system to maximize the energy harvesting in a particular location," in AIP Conference Proceedings, 2013, vol. 1556, p. 156.

[34] S. Askins, M. Victoria, R. Herrero, C. Domínguez, I. Antón, G. Sala, F. Dimroth, S. Kurtz, G. Sala, and A. W. Bett, "Effects of Temperature on Hybrid Lens Performance," in AIP Conference Proceedings, 2011, pp. 57-60.

[35] V. D. Rumyantsev, N. Y. Davidyuk, E. A. lonova, P. V. Pokrovskiy, N. A. Sadchikov, V. M. Andreev, A. W. Bett, R. D. McConnell, G. Sala, and F. Dimroth, "Thermal Regimes of Fresnel Lenses and Cells in' All-Glass' HCPV Modules," in AIP Conference Proceedings, 2010, vol. 1277, p. 89.

[36] T. Hornung, M. Steiner, and P. Nitz, "Estimation of the influence of Fresnel lens temperature on energy generation of a concentrator photovoltaic system," Sol. Energy Mater. Sol. Cells, vol. 99, pp. 333-338, Apr. 2012.

[37] S. Askins, C. Domínguez, I. Antón, and G. Sala, "An indoor/outdoor method for CPV power rating: Application to draft IEC standard," in 25th European Photovoltaic Solar Energy Conference and Exhibition - 5th World Conference on Photovoltaic Energy Conversion, Valencia, Spain, 2010, pp. 110-113.

[38] H. Nagai, K. Araki, K. Hobo, P. Zamora, P. Benítez, J. C. Miñano, K. Nishioka, Y. Ota, I. Luque Heredia, J. Hashimoto, T. Ueda, Y. Hishikawa, R. Herrero, S. Askins, I. Antón, R. Núñez, G. Sala, M. Steiner, M. Niemeyer, G. Siefer, and A. W. Bett, "Development of the new DFK CPV module by NGCPV Japan-EU collaboration," in Proceedings of 6th World Conference on Photovoltaic Energy Conversion, Kyoto, Japan, 2014.

[39] IEC committee, "IEC 62670-1 - CONCENTRATOR PHOTOVOLTAIC (CPV) PERFORMANCE TESTING Part 1: Standard Conditions," IEC, 2013.

[40] K. Emery, D. Myers, and S. Kurtz, "What is the appropriate reference spectrum for characterizing concentrator cells?," in Conference Record of the Twenty-Ninth IEEE Photovoltaic Specialists Conference, 2002, 2002, pp. 840-843.

[41] W. E. McMahon, S. Kurtz, K. Emery, and M. S. Young, "Criteria for the design of GaInP/GaAs/Ge triple-junction cells to optimize their performance outdoors," in Conference Record of the Twenty-Ninth IEEE Photovoltaic Specialists Conference, 2002, 2002, pp. 931-934.

[42] K. Araki and M. Yamaguchi, "Influences of spectrum change to 3-junction concentrator cells," Sol. Energy Mater. Sol. Cells, vol. 75, no. 3-4, pp. 707-714, Feb. 2003.

[43] S. P. Philipps, G. Peharz, R. Hoheisel, T. Hornung, N. M. Al-Abbadi, F. Dimroth, and A. W. Bett, "Energy harvesting efficiency of III-V triple-junction concentrator solar cells under realistic spectral conditions," Sol. Energy Mater. Sol. Cells, vol. 94, no. 5, pp. 869-877, May 2010.

[44] G. S. Kinsey and K. M. Edmondson, "Spectral response and energy output of concentrator multijunction solar cells," Prog. Photovolt. Res. Appl., vol. 17, no. 5, pp. 279-288, 2009.

[45] M. P. Lumb, A. L. Dobbin, D. B. Bushnell, K. H. Lee, and T. N. D. Tibbits, "Comparing The Energy Yield of (III-V) Multi-Junction Cells With Different Numbers Of Sub-Cells," in AIP Conference Proceedings, 2010, vol. 1277, pp. 299-302. 
[46] M. Victoria, R. Herrero, C. Domínguez, S. Askins, I. Antón, and G. Sala, "Indoor characterization of non uniform light distribution due to concentration optics and its effects on solar cell performance," in 25th European Photovoltaic Solar Energy Conference and Exhibition - 5th World Conference on Photovoltaic Energy Conversion, Valencia, Spain, 2010, pp. 143-146.

[47] D. Aiken, M. Stan, C. Murray, P. Sharps, J. Hills, and B. Clevenger, "Temperature dependent spectral response measurements for III-V multi-junction solar cells," in Conference Record of the Twenty-Ninth IEEE Photovoltaic Specialists Conference, 2002, 2002, pp. 828-831.

[48] F. Pérez, B. E. Granger, and J. D. Hunter, "Python: An Ecosystem for Scientific Computing," Comput. Sci. Eng., vol. 13, no. 2, pp. 13-21, Mar. 2011.

[49] D. A. Green, "A colour scheme for the display of astronomical intensity images," ArXiv Prepr. ArXiv11085083, 2011. 